\title{
Taping for conditions of the musculoskeletal system: an evidence map review
}

Zachary A. Cupler ${ }^{1 *}$ (D, Muhammad Alrwaily ${ }^{2,3}$, Emily Polakowski ${ }^{4}$, Kevin S. Mathers $^{5}$ and Michael J. Schneider ${ }^{6}$

\begin{abstract}
Background: Taping is a common treatment modality used by many rehabilitation providers. Several types of tapes and taping methods are used in the treatment of musculoskeletal dysfunction and pain.

Purpose: To summarize and map the evidence related to taping methods used for various joints and conditions of the musculoskeletal system, and to provide clinicians and researchers with a user-friendly reference with organized evidence tables.

Data sources: The PEDro, CINAHL, Cochrane Database of Systematic Reviews, Cochrane Central Register for Controlled Trials, PubMed, and PROSPERO databases were searched from inception through October 31, 2019.

Study selection: Eligible studies were selected by two independent reviewers and included either systematic reviews (SRs) or randomized controlled trials (RCTs) and included a musculoskeletal complaint using a clinical outcome measure.
\end{abstract}

Data extraction: Data was extracted by two investigators independently. Risk of bias and quality were assessed using A MeaSurement Tool to Assess systematic Reviews (AMSTAR) for SRs or the Physiotherapy Evidence Database (PEDro) scale for RCTs. The protocol was registere-d with PROSPERO (CRD42019122857).

Data synthesis: Twenty-five musculoskeletal conditions were summarized from forty-one SRs and 127 RCTs. There were 6 SRs and 49 RCTs for spinal conditions. Kinesio tape was the most common type of tape considered. Four evidence tables representing the synthesized SRs and RCTs were produced and organized by body region per condition.

Limitations: Inclusion of only English language studies. Also, the heterogeneous nature of the included studies prevented a meta-analysis.

Conclusions: There is mixed quality evidence of effectiveness for the different types of taping methods for different body regions and conditions. All of the SRs and RCTs found during our search of the taping literature have been organized into a series of appendices. A synthesis of the results have been placed in evidence tables that may serve as a useful guide to clinicians and researchers.

Keywords: Taping, Musculoskeletal, Evidence map

\footnotetext{
* Correspondence: zachary.cupler@va.gov

'Physical Medicine \& Rehabilitation Services, Butler VA Healthcare System,

353 N. Duffy Road, Butler, Pennsylvania, USA

Full list of author information is available at the end of the article
}

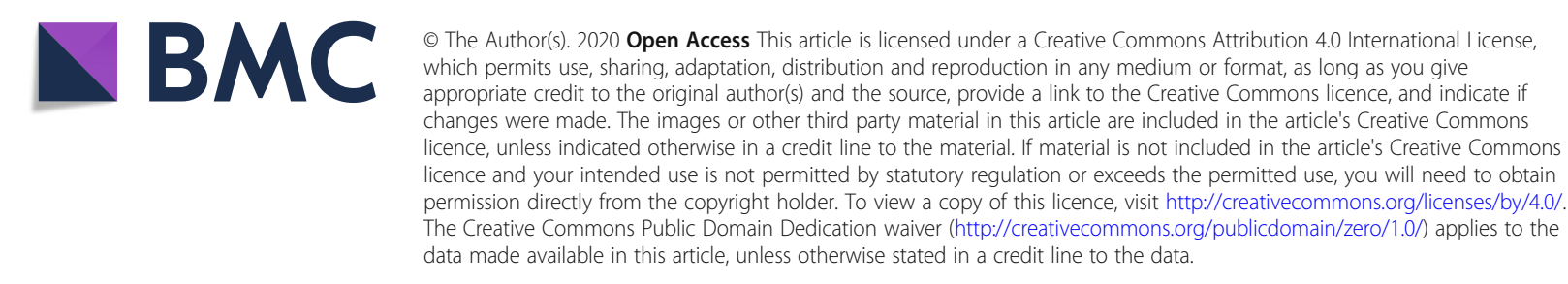




\section{Introduction}

\section{Description of the condition}

Musculoskeletal conditions are reported by approximately one in two adults in the United States, and are considered amongst the top five medical conditions reported in 2015 [1]. These conditions are a major contributor to disability, accounting for $17.1 \%$ of years lived with disability [1]. The disability and reduced quality of life resulting from these conditions are reported to be at much higher rates than hypertension and elevated cholesterol levels [1]. The major contributors to this disability are low back pain, neck pain, [2] hip and knee osteoarthritis [3], shoulder complex conditions amongst other joints [4]. Collectively, these conditions are commonly seen in rehabilitation clinics and taping is a very popular modality used in their management.

\section{Description of the intervention}

The use of taping as a treatment method has been reported in the literature as early as 1969 [5]. Taping is used to treat acute and chronic musculoskeletal complaints including, but not limited to, pain, function, joint instability, and edema [6]. Prophylactic use of tape to prevent sporting injuries has also been reported [5, 7, 8]. At the 2012 Olympic games in London, taping was one of the five most frequently used treatment modalities, accounting for $8.9 \%$ of used interventions [9]. Multiple methods of taping are available, including rigid taping, Kinesio tape, McConnell and Mulligan. Each of these types of taping has been associated with specific therapeutic mechanisms that we detail below.

\section{Rigid (athletic) taping}

Rigid taping is a tan-colored adhesive strap that is used primarily by athletes to prevent or reduce the chance of injury. Rigid tape, such as leukotape, is frequently applied in a standardized protocol for each joint. The application begins with an under-wrap to reduce skin irritation, with rigid tape applied over the under-wrap on the area of injury. For each joint, a rigid tape protocol is a pattern of multiple straps applied to the body part to secure the joint in a specific position while allowing the individual to participate in the athletic activity. A specific sub-type of rigid taping for abnormal pronation is described in the literature at times as "low dye tape" [6]. This method of taping is used for purposes such as reducing pain, providing proprioceptive feedback during activity, and limiting excessive joint motion [10].

\section{Kinesio taping}

Kinesio tape (KT) was developed in Japan by Kenzo Kase, a chiropractor and acupuncturist, as an alternative tape and methodology to the traditional rigid taping materials and methods [11]. After the dramatic increase in its usage during the Olympics, KT has become a popular taping method in daily life, sports, as well as by various health care practitioners [11]. KT is an adhesive elastic tape that comes in numerous colors and patterns that is applied directly to the skin without the need for underwrap. KT is designed to mimic the elasticity of the skin. Theoretically, the KT is presumed to target different receptors within the somatosensory system with the intent to lessen pain and promote lymphatic drainage by lifting the skin to increase interstitial space [12]. Numerous trials and systematic reviews have been conducted to investigate the mechanisms of $\mathrm{KT}[7,8,13-17]$.

\section{McConnell taping}

McConnell taping (Mc-T) is a method pioneered in 1984, by Jenny McConnell, an Australian physical therapist [18]. This method uses a more rigid, adhesive type of tape similar to the traditional athletic tape. The Mc-T is primarily advocated to help with alignment of the patella in patients with patellofemoral pain [19], however, the application of Mc-T has been described for other joints, such as the shoulder and hip [6]. A common concern in individuals with patellofemoral pain is that the pain is presumed to be due to incorrect tracking of the patella on the femur. This tape purports to address these problems by attempting to realign the tracking of the knee. This taping method provides proprioception and mechanical pressure on the patella in one specific direction so that the patella can move freely without contacting other parts of the femur during joint articulation and thus reducing pain [19-21].

\section{Mulligan taping}

Mulligan taping is an adhesive strap method similar to rigid taping. This tape is used as a supplement to the Mulligan mobilization with movement procedure, a therapeutic technique using manual force that is applied to a joint and sustained in specific direction. The manual therapy technique of Mulligan is intended to allow painless motion of a previously painful joint [22]. After the Mulligan mobilization is conducted, rigid tape can be applied to the body region in the same direction as the manual force. This is thought to extend the benefit of the mobilization with movement after the treatment session ends [23].

\section{Why this evidence map is important}

There are numerous systematic reviews (SRs) and randomized controlled trials (RCTs) that have been conducted on the effectiveness of taping on various body regions and musculoskeletal conditions. These studies have included different types of taping methods, varied outcome measures, diverse patient populations for different body regions, and sometimes yield contradictory 
conclusions. Because of this variety of methods and measures, it has become difficult for clinicians and researchers to appraise evidence about taping effectiveness. Therefore, this evidence map sought to comprehensively summarize, synthesize, and organize the abundant literature about the effectiveness of various taping methods on the musculoskeletal system. This evidence mapping seeks to develop a concise, and comprehensive clinicfriendly tool that summarizes the evidence regarding the effectiveness of taping for the musculoskeletal system while also identifying gaps in knowledge and guide future research [24].

\section{Methods}

Evidence mapping is a variant form of a systematic review. The methodology involved for this evidence map begins with a systematic literature search that shares many characteristics of a systematic review, such as defined search date terms, study selection, inclusion and exclusion parameters, data extraction, bias/quality assessment, data synthesis, and study conclusions. Evidence maps, as compared to systematic reviews, were most commonly defined as reviews of evidence to identify research gaps in addition to producing user-friendly end products such as clinical tools [24]. This study was registered in PROSPERO (CRD42019122857).

\section{Study selection \\ Types of studies}

We included SRs from December 31, 2007 to October 31, 2019 and RCTs from inception to October 31, 2019.

\section{Type of participants}

We included studies that have participants aged 18 years or older presenting with clinical musculoskeletal complaints.

\section{Inclusion/exclusion criteria}

We included all studies that investigated any type of taping on musculoskeletal conditions. We excluded studies involving only asymptomatic participants, reporting no clinical outcome measures, reporting results limited to less than 1 day following intervention, or manuscripts was reported in a language other than English.

\section{Interventions}

We included all SRs and RCTs that involved a taping method as an intervention, without restriction to any specific type of tape.

\section{Types of outcome measures}

We included studies that involved clinically-relevant outcome measures such as pain intensity, disability, range of motion, and muscle strength, etc. We excluded studies that only reported biomechanical observations or basic science outcome measures such as labspecific measures (e.g. EMG activity, proprioception, biomarkers, etc.)

\section{Data sources and searches}

Electronic search: The keywords used to perform our search were informed by current SRs of the taping literature, and included these search terms: "Tape" OR "tapes" OR "taping" OR "strap" OR "strapping”. We searched the following databases: Physiotherapy Evidence Database (PEDro), Cumulative Index to Nursing and Allied Health Literature (CINAHL), Cochrane Database of Systematic Reviews, Cochrane Central Register for Controlled Trials (CENTRAL), PubMed, and PROSPERO. Searching other resources: To be more comprehensive, we hand searched the evidence tables within all included SRs for relevant RCTs that may have been missed in our electronic search.

\section{Data selection, extraction, and quality assessment}

Two reviewers (MA, ZC) independently selected potentially relevant SRs and RCTs based first on the title, followed secondly by a review of the abstract. We used consensus to resolve disagreements concerning selection and inclusion of SRs and RCTs. Whenever disagreement persisted, a third reviewer (MS) was consulted to adjudicate the disagreement. We evaluated manuscripts that could be retrieved in full-text format and were published in English.

Two reviewers (MA, ZC) independently extracted the data using a standardized table format for all included SRs and RCTs. We used consensus to resolve discrepancies concerning data extraction. Whenever disagreement persisted, a third reviewer (MS) was consulted for adjudication. The data extracted from SRs included: author, year of publication, title, population studied, search dates, number of included studies, intervention, summary of results, and A MeaSurement Tool to Assess systematic Reviews (AMSTAR) rating. The data extracted from RCTs included: author, year of publication, title, population studied, sample size, intervention groups, outcomes time points, results, key author conclusion, and PEDro quality scores.

\section{Assessment of risk of bias and quality in included studies}

For SRs, we had two reviewers (KM, MA) utilize the AMSTAR rating criteria to assess the methodological quality of SRs. For RCTs, we extracted quality ratings from PEDro whenever available. If an RCT rating was not available, then we had two reviewers (MA, ZC) independently assess the quality using the PEDro scale criteria. We used consensus for rating SRs and RCTs. If 
disagreement persisted during assessment, a third reviewer (MS) was consulted for adjudication.

\section{Data synthesis and analysis}

With the busy clinician in mind, we created evidence tables to provide an efficient clinician-friendly way to view the taping literature. We were unable to make our recommendations using the identified SRs because they frequently included contradictory statements made from shared or overlapping RCTs. Rather, we synthesized our recommendations from the RCTs that are retrieved from our database search, and from the RCTs identified within each SRs. We sorted the RCTs for each respective condition, and then we examined the results, conclusions and PEDro scores to make our recommendations.

The PEDro scale is a 10-item tool that provides the user a rapid way to determine internal validity and quality to guide clinical decision-making [25]. Key characteristics considered in the grading schema include: randomized allocation, group baselines, blinding, attainment of primary outcome for $85 \%$ of subjects initially allocated, intention to treat, between group comparisons, point measurements, and measurements of variability for at least one outcome. Previous work has suggested an RCT scoring a minimum of $6 / 10$ is considered to be of 'moderate to high quality' [26]. To further enhance clinical efficiency, we consolidated PEDro grading to 3 levels: strong, moderate, and weak (see below).

\section{Grading of the evidence}

The evidence grades were trichotomized into 3 levels of strength: strong, moderate, and low (Table 1). For each level of strength, we used the following criteria:

\section{Strong level evidence}

To achieve this evidence rating, the results must stem from preponderance of high-quality RCTs (PEDro 7 10). This grade of evidence includes well-designed, well-

Table 1 Key to Evidence Summary Tables

\begin{tabular}{|c|c|c|}
\hline $\begin{array}{l}\text { Quality of } \\
\text { Evidence }\end{array}$ & $\begin{array}{l}\text { Summary of } \\
\text { Evidence }\end{array}$ & Definition \\
\hline \multirow{2}{*}{ Strong } & Recommend & $\begin{array}{l}\text { The results indicate a positive outcome for taping. The conclusion is unlikely to be } \\
\text { changed by future RCTs. }\end{array}$ \\
\hline & Discouraged & $\begin{array}{l}\text { The results indicate a negative outcome for taping. The conclusion is unlikely to be } \\
\text { changed by future RCTs. }\end{array}$ \\
\hline \multirow{3}{*}{ Moderate } & Favorable & $\begin{array}{l}\text { The results indicate a positive trend for taping. This conclusion remains to be confirmed } \\
\text { by future higher quality RCTs. }\end{array}$ \\
\hline & Equivocal & $\begin{array}{l}\text { The results indicate an unclear trend for taping. This conclusion remains to be clarified by } \\
\text { future higher quality RCTs. }\end{array}$ \\
\hline & Unfavorable & $\begin{array}{l}\text { The results indicate a negative trend for taping. This conclusion remains to be confirmed } \\
\text { by future higher quality RCTs. }\end{array}$ \\
\hline \multirow{2}{*}{ Weak } & Promising & $\begin{array}{l}\text { The results are positive but inconclusive due to poor methodology and/or a limited number } \\
\text { of RCTs. The conclusion is likely to be impacted by future higher quality RCTs. }\end{array}$ \\
\hline & Unclear & $\begin{array}{l}\text { The results are negative or equivocal due to poor methodology and/or a limited number of } \\
\text { RCTs. The conclusion is likely to be impacted by future higher quality RCTs. }\end{array}$ \\
\hline & & $\begin{array}{l}\text { An empty white cell represents an absence or insufficient amount of evidence available to } \\
\text { make a recommendation for this condition for this particular type of tape. Recommendations } \\
\text { will be established by future high quality RCTs. }\end{array}$ \\
\hline
\end{tabular}




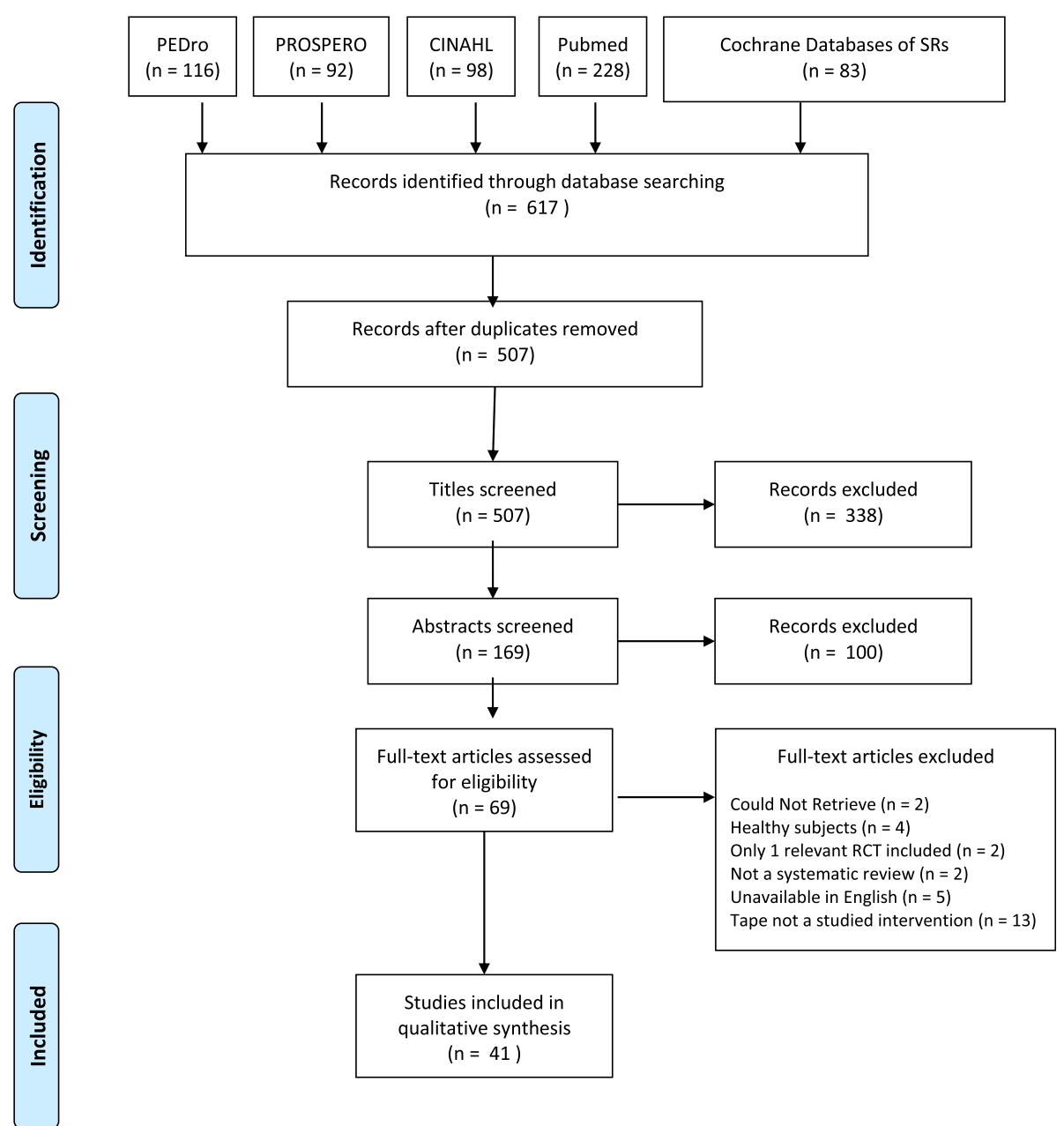

Fig. 1 Flow diagram for systematic review selection

conducted studies with representative populations. The studies' conclusions must be in reasonable agreement. The conclusions drawn from a strong level of evidence are considered unlikely to be changed by the results of future RCTs unless improved research methodologies, including sham and choice of control interventions, are incorporated into future studies.

\section{Moderate level evidence}

To achieve this evidence rating, the results should be based on at least one higher-quality RCT; or a preponderance of higher-quality RCTs with inconsistent conclusions; or a preponderance moderate-quality RCTs (PEDro 4 - 6) with harmonious results. The conclusions from moderate level of evidence are likely to be changed by the results of future, more rigorous RCTs.

\section{Weak level evidence}

To be at this level of evidence, the results are based on at least one moderate-quality RCT; or a preponderance of moderate-quality RCTs with inconsistent conclusions; or a preponderance of low-quality RCTs (PEDro $0-3$ ). The conclusion is insufficient to identify effectiveness for conditions studied.

\section{Results}

The literature search process for SRs is summarized in Fig. 1, and for RCTs in Fig. 2. Our search identified 41 SRs and 127 RCTs for inclusion, with a total of 25 musculoskeletal conditions summarized. The SRs were arranged in evidence tables and organized by body region: lower extremity, upper extremity and spinal conditions, respectively (Appendix 1 File). The majority of the SRs (22/41) discussed musculoskeletal conditions related to the lower extremity (Table 2).

The RCTs were also arranged in evidence tables and organized by body region: lower extremity, upper extremity, spinal conditions, and "not otherwise classified" (Table 3). Due to the plethora of available RCTs, we further subdivided each body region into its respective 


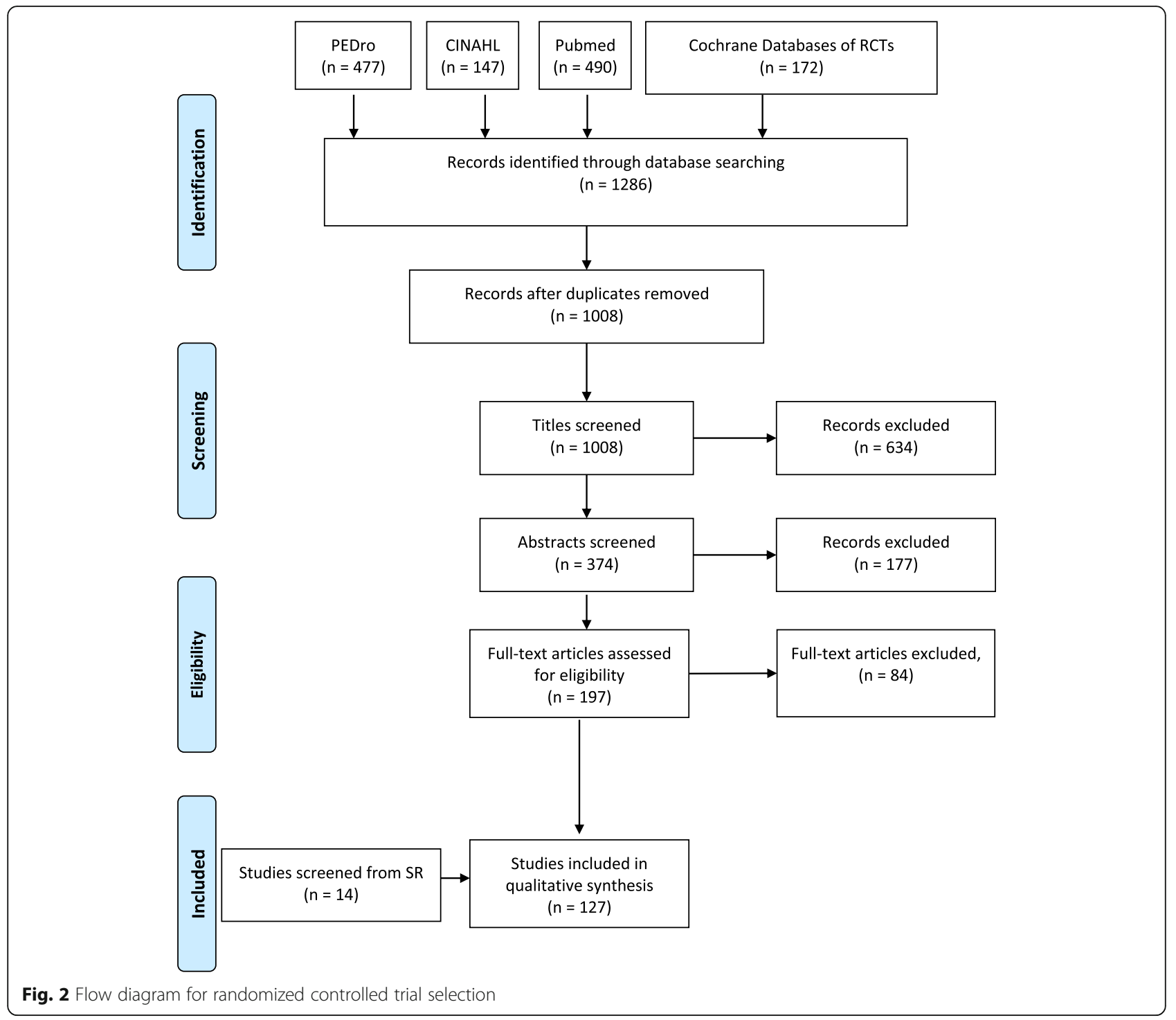

joints: knee, ankle, foot, shoulder, elbow and hand/wrist, lumbar spine, thoracic spine, cervical spine, and temporomandibular joint (Appendix 2 File).

In the following section, we will detail the findings of the SRs and RCTs for each body region.

\section{Lower extremity conditions}

Twenty-two of the total 41 SRs were related to the lower extremity conditions. The SRs of the lower extremity had an overall AMSTAR score that ranged between 2.5 to 10 (out of a maximum score of 11). Forty-two of the total 127 (33.6\%) RCTs were related to lower extremity conditions. The RCTs of the lower extremities had an overall PEDro score that ranged between 1 to 8 (out of a maximum score of 10). Six different lower extremity conditions were identified and evaluated for taping procedures.

\section{Hip}

There were no SRs or RCTs identified about the hip that met the inclusion criteria.

\section{Knee}

There were 9 SRs related to the knee or patellofemoral joints (Appendix 1 File: Appendix 1A), with AMSTAR scores ranging from 4 to 10 . Seven of the SRs studied taping strategies related to patellofemoral pain syndrome (PFPS) or anterior knee pain [18, 27-32]; one SR studied rigid taping for knee osteoarthritis (OA) [33], and one SR studied elastic taping for knee OA [34]. There were 27 RCTs related to PFPS [35-42], knee osteoarthritis [43-59], patellar dislocation [60], and tibial stress syndrome [61] (Appendix 2 File: Appendix 2A). The overall PEDro scores for these RCTs ranged from 4 to 8 . 
Table 2 Distribution of included articles by region: Systematic Reviews

\begin{tabular}{ll}
\hline SR by region & $\mathbf{2 2}$ \\
\hline Lower extremity: & 0 \\
Hip & 9 \\
Knee & 7 \\
Ankle & 6 \\
Foot & $\mathbf{1 0}$ \\
Upper extremity: & 8 \\
Shoulder & 1 \\
Elbow & 1 \\
Hand/Wrist & $\mathbf{6}$ \\
Spine: & 5 \\
Lumbar & 0 \\
Thoracic & 1 \\
Cervical & 1 \\
TMJ & 0 \\
Not otherwise classified & $\mathbf{4}$ \\
\hline
\end{tabular}

Patellofemoral pain syndrome (PFPS) Eight studies investigated the effect of taping on PFPS. Two RCTs utilized KT and six RCTs utilized Mc-T.

\section{Evidence summary (Table 4)}

- There is moderate evidence that the inclusion of KT in the treatment plan of PFPS is equivocal.

Table 3 Distribution of included articles by region: Randomized Controlled Trials

\begin{tabular}{ll}
\hline RCT by region & \\
\hline Lower extremity: & $\mathbf{4 2}$ \\
Hip & 0 \\
Knee & 27 \\
Ankle & 8 \\
Foot & 7 \\
Upper extremity: & $\mathbf{3 3}$ \\
Shoulder & 19 \\
Elbow & 7 \\
Hand/Wrist & 7 \\
Spine: & $\mathbf{4 9}$ \\
Lumbar & 23 \\
Thoracic & 2 \\
Cervical & 20 \\
TMJ & 4 \\
Not otherwise classified: & $\mathbf{3}$ \\
\hline
\end{tabular}

- There is moderate evidence that the inclusion of Mc-T in the treatment plan of PFPS is equivocal.

Knee osteoarthritis (OA) There were seventeen studies that investigated the effect of taping on knee OA. Two RCTs utilized rigid taping, ten RCTs utilized KT and five RCTs utilized Mc-T.

\section{Evidence summary (Table 4)}

- There is strong evidence that rigid taping is a useful adjunctive treatment in the management of pain and function in the short-term for patients with knee OA.

- There is moderate evidence that the inclusion of KT in the treatment of knee OA is favorable.

- There is moderate evidence that Mc-T is favorable in the treatment of pain and function for knee OA.

Primary lateral patellar dislocation There was one RCT that investigated the effects of rigid taping for lateral patellar dislocation with moderate risk of bias.

\section{Evidence summary (Table 4)}

- There is promising weak evidence that rigid taping is superior to cast immobilization for recurrence of lateral patellar dislocation.

Tibial stress syndrome There was one RCT that investigated the effects of KT for shin splints with high risk of bias.

\section{Evidence summary (Table 4)}

- There is promising weak evidence that $\mathrm{KT}$ is superior to orthotics for the management of tibial stress syndrome with respect to pain and function.

\section{Ankle}

There were seven SRs related to the ankle or talocrural joint (Appendix 1 File: Appendix 1B) with AMSTAR scores ranging from 2.5 to 9 . All of the SRs investigated taping strategies to treat ankle sprains [7, 76-81]. There were eight RCTs related to ankle sprains [5, 62-68]. The overall PEDro scores ranged from 1 to 8.

Ankle sprains Seven RCTs utilized rigid taping and one RCT utilized KT (Appendix 2 File: Appendix 2B). No studies investigated Mulligan taping or Mc-T for ankle sprains.

\section{Evidence summary (Table 4)}

- There is moderate evidence that the inclusion of rigid taping in the treatment plan of grade II and grade III ankle sprains is equivocal. 
Table 4 Lower extremity conditions interpretation of the evidence

\begin{tabular}{|c|c|c|c|c|}
\hline \multirow[t]{2}{*}{ Lower Extremity Conditions } & \multirow[t]{2}{*}{ Intervention } & \multicolumn{3}{|c|}{ Quality of Evidence } \\
\hline & & Weak & Moderate & High \\
\hline \multirow{4}{*}{$\begin{array}{l}\text { Patellofemoral Pain } \\
\text { Syndrome or Anterior } \\
\text { Knee Pain }\end{array}$} & Rigid taping & & & \\
\hline & Kinesio taping $[35,41]$ & & Equivocal & \\
\hline & Mulligan taping & & & \\
\hline & $\begin{array}{l}\text { McConnell taping } \\
{[36-40,42]}\end{array}$ & & Equivocal & \\
\hline \multirow{4}{*}{ Knee Osteoarthritis } & Rigid taping $[44,48]$ & & & Recommended \\
\hline & $\begin{array}{l}\text { Kinesio taping } \\
{[43,46,47,49-53,57,59]}\end{array}$ & & Favorable & \\
\hline & Mulligan taping & & & \\
\hline & $\begin{array}{l}\text { McConnell taping } \\
{[45,54-58]}\end{array}$ & & Favorable & \\
\hline \multirow{4}{*}{$\begin{array}{l}\text { Primary Lateral Patellar } \\
\text { Dislocation }\end{array}$} & Rigid taping [60] & Promising & & \\
\hline & Kinesio taping & & & \\
\hline & Mulligan taping & & & \\
\hline & McConnell taping & & & \\
\hline \multirow{4}{*}{ Tibial Stress Syndrome } & Rigid taping & & & \\
\hline & Kinesio taping [61] & Promising & & \\
\hline & Mulligan taping & & & \\
\hline & McConnell taping & & & \\
\hline \multirow{4}{*}{$\begin{array}{l}\text { Ankle Sprain } \\
\text { (Grade I, II, III) }\end{array}$} & $\begin{array}{l}\text { Rigid taping } \\
{[5,62-67]}\end{array}$ & & Equivocal & \\
\hline & Kinesio taping [68] & & Unfavorable & \\
\hline & Mulligan taping & & & \\
\hline & McConnell taping & & & \\
\hline \multirow{4}{*}{$\begin{array}{c}\text { Plantar Fasciitis or Plantar } \\
\text { Heel Pain }\end{array}$} & $\begin{array}{l}\text { Rigid taping } \\
\text { [69-73] }\end{array}$ & & Equivocal & \\
\hline & Kinesio taping [74] & Promising & & \\
\hline & Mulligan taping [75] & Promising & & \\
\hline & McConnell taping & - & - & - \\
\hline
\end{tabular}


- There is moderate evidence that the inclusion of KT in the treatment plan of grade II and grade III ankle sprains is unfavorable.

\section{Foot}

There were six SRs related to the foot excluding the ankle or talocrural joint (Appendix 1 File: Appendix 1C), with AMSTAR scores ranging from 5 to 10 . Three of the SRs assessed taping strategies to treat plantar heel pain and plantar fasciitis [82-84] and three SRs investigated taping for treatment of excessive foot pronation [85-87]. There were seven RCTs related to plantar fasciitis and plantar heel pain (Appendix 2 File: Appendix 2C). Five RCTs investigated rigid taping [69-73], one RCT investigated KT [74] and one RCT investigated Mulligan taping [75]. No study investigated Mc-T. The overall PEDro scores ranged from 3 to 7.

\section{Plantar heel pain Evidence summary (Table 4)}

- There is moderate evidence that the inclusion of rigid taping in the treatment of plantar fasciitis or heel pain is equivocal.

- There is promising weak evidence that KT taping may provide adjunctive benefit to multimodal conservative treatment for plantar fasciitis or heel pain.

- There is promising weak evidence that Mulligan taping may provide adjunctive benefit to multimodal conservative treatment for plantar fasciitis or heel pain.

\section{Upper extremity conditions}

Of the $41 \mathrm{SRs}$, ten were related to the upper extremities conditions with overall AMSTAR scores that ranged between 6 to 10 . Of the 127 RCTs, 33 (26.0\%) were related to the upper extremities conditions with overall PEDro scores that ranged between 3 to 9 . Six conditions of the upper extremity were identified and evaluated for taping procedures.

\section{Shoulder}

There were eight SRs related to the shoulder, scapula, and glenohumeral joint (Appendix 1 File: Appendix 1D) with overall AMSTAR scores ranging from 6-10. All SRs evaluated taping strategies for subacromial impingement syndrome or rotator cuff tendinopathy [88-95]. There were nineteen RCTs investigating taping strategies for the treatment of SIS (Appendix 2 File: Appendix 2D). Three RCTs investigated rigid taping [96-98], fifteen RCTs investigated KT [99-113] and one RCT investigated Mulligan taping [114]. No study investigated Mc$\mathrm{T}$ for SIS. The overall PEDro scores ranged from 4 to 9 .
Subacromial impingement syndrome (SIS) Evidence summary (Table 5)

- There is moderate evidence that rigid taping provides additional improvement to exercise and manual therapy for the treatment of SIS conditions.

- There is moderate evidence that the inclusion of KT in the treatment plan of SIS is equivocal.

- There is promising weak evidence that Mulligan taping adds benefit to manual therapy in the treatment of SIS conditions.

\section{Elbow}

There was one SR of taping for lateral epicondylalgia (Appendix 1 File: Appendix 1E) with an AMSTAR rating of 9 [129]. There were seven RCTs studying the effects of taping for conditions of the elbow, humeroulnar joint, humeroradial joint or proximal radioulnar joint (Appendix 2 File: Appendix 2E) with PEDros score that ranged from 3 to 7 . All RCTs studied tennis elbow or lateral epicondylalgia with three studies evaluating the effect of rigid taping [115-117] and four studies evaluating the effect of KT [118-121]. No study investigated Mulligan taping or Mc-T for lateral epicondylalgia.

\section{Lateral epicondylalgia Evidence summary (Table 5)}

- There is promising weak evidence that rigid taping is a useful adjunct to physical therapy for pain or disability in the treatment of lateral epicondylalgia.

- There is moderate evidence that the use of KT as adjunct to physical therapy for pain or disability in the treatment of lateral epicondylalgia is equivocal.

\section{Hand and wrist}

There was one SR related to the wrist and hand, (Appendix 1 File: Appendix 1F) with an AMSTAR score of 8 [130]. There were seven RCTs investigating taping strategies for the treatment of conditions of the hand and wrist with PEDro scores ranging from 5 to 9 (Appendix 2 File: Appendix 2F). Four RCTs investigated KT for carpal tunnel syndrome [122-125], one RCT assessed KT for de Quervain's syndrome [126], one RCT investigated rigid tape for dorsal wrist pain [127], and one RCT evaluated elastic tape configuration for OA of the proximal interphalangeal joint [128]. No studies investigated Mulligan taping or Mc- $\mathrm{T}$ musculoskeletal conditions of the wrist or hand.

Carpal tunnel syndrome Evidence summary (Table 5) 
Table 5 Upper extremity conditions interpretation of the evidence

\begin{tabular}{|c|c|c|c|c|}
\hline \multirow[t]{2}{*}{ Upper Extremity Conditions } & \multirow[t]{2}{*}{ Intervention } & \multicolumn{3}{|c|}{ Quality of Evidence } \\
\hline & & Weak & Moderate & High \\
\hline \multirow{4}{*}{$\begin{array}{c}\text { Subacromial } \\
\text { Impingement(Pain } \\
\text { Syndrome }\end{array}$} & Rigid taping [96-98] & & Favorable & \\
\hline & $\begin{array}{l}\text { Kinesio taping } \\
{[99-113]}\end{array}$ & & Equivocal & \\
\hline & Mulligan taping [114] & Promising & & \\
\hline & McConnell taping & & & \\
\hline \multirow{4}{*}{$\begin{array}{l}\text { Tennis Elbow or Lateral } \\
\text { Epicondylitis or } \\
\text { Epicondylagia or Lateral } \\
\text { Tendinosis }\end{array}$} & $\begin{array}{l}\text { Rigid taping } \\
{[115-117]}\end{array}$ & Promising & & \\
\hline & $\begin{array}{l}\text { Kinesio taping } \\
{[118-121]}\end{array}$ & & Equivocal & \\
\hline & Mulligan taping & & & \\
\hline & McConnell taping & & & \\
\hline \multirow{4}{*}{ Carpal Tunnel Syndrome } & Rigid taping & & & \\
\hline & $\begin{array}{l}\text { Kinesio taping } \\
{[122-125]}\end{array}$ & & Equivocal & \\
\hline & Mulligan taping & & & \\
\hline & McConnell taping & & & \\
\hline \multirow{4}{*}{ de Quervain's Syndrome } & Rigid taping & & & \\
\hline & Kinesio taping [126] & Promising & & \\
\hline & Mulligan taping & & & \\
\hline & McConnell taping & & & \\
\hline \multirow{4}{*}{ Dorsal Wrist Pain } & Rigid taping [127] & Promising & & \\
\hline & Kinesio taping & & & \\
\hline & Mulligan taping & & & \\
\hline & McConnell taping & & & \\
\hline \multirow{4}{*}{$\begin{array}{l}\text { Osteoarthritis of the } \\
\text { Proximal Interphalangeal } \\
\text { Joint }\end{array}$} & Rigid taping & & & \\
\hline & Kinesio taping [128] & & Equivocal & \\
\hline & Mulligan taping & & & \\
\hline & McConnell taping & & & \\
\hline
\end{tabular}


Table 6 Spinal conditions interpretation of the evidence

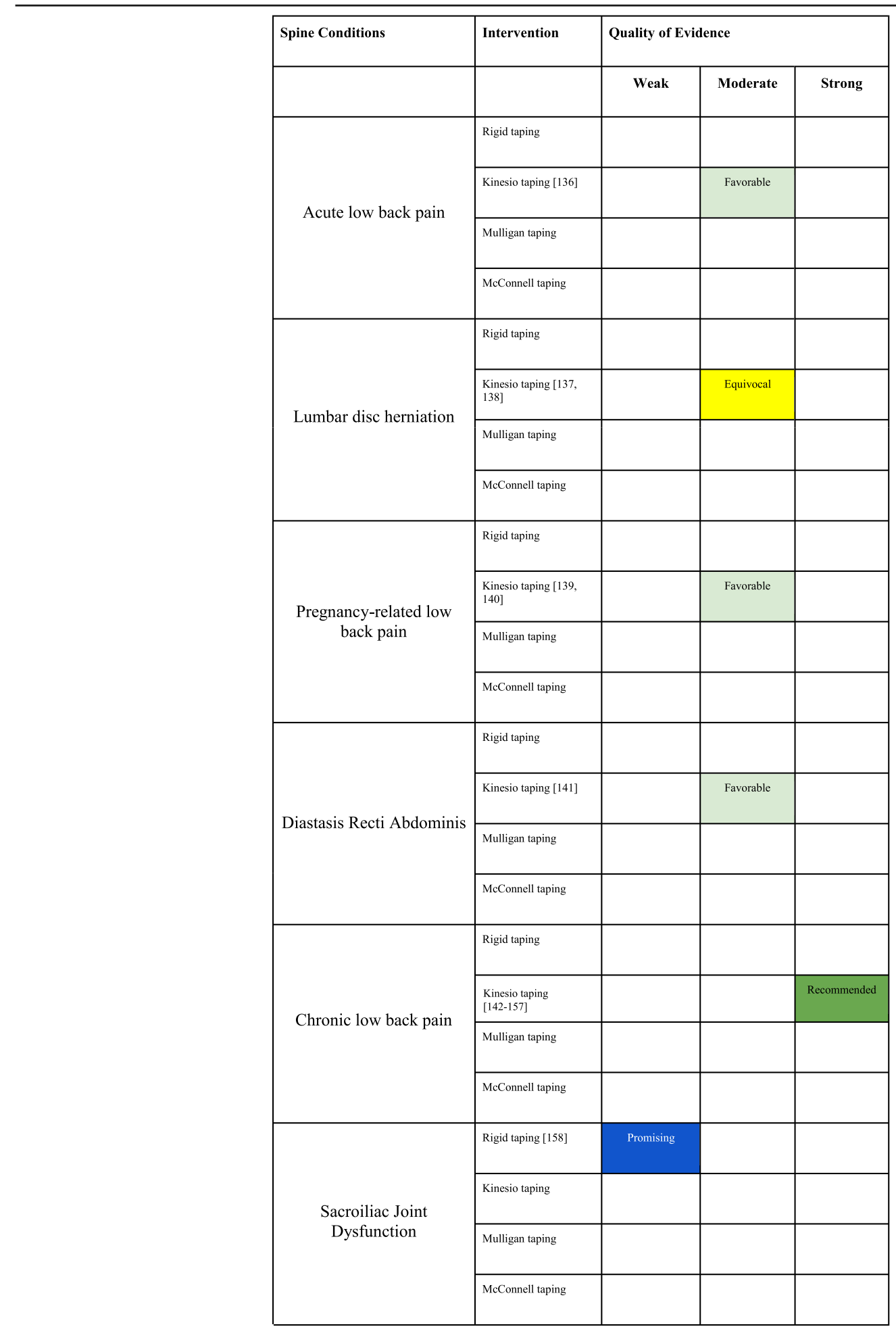


Table 6 Spinal conditions interpretation of the evidence (Continued)

\begin{tabular}{|c|c|c|c|}
\hline \multirow{4}{*}{$\begin{array}{c}\text { Postmenopausal Thoracic } \\
\text { Hyperkyphosis } \\
\text { (Osteoporosis) }\end{array}$} & Rigid taping & & \\
\hline & $\begin{array}{l}\text { Kinesio taping }[159, \\
160]\end{array}$ & Equivocal & \\
\hline & Mulligan taping & & \\
\hline & McConnell taping & & \\
\hline \multirow{4}{*}{ Non-specific neck pain } & Rigid taping & & \\
\hline & $\begin{array}{l}\text { Kinesio taping } \\
{[161-170]}\end{array}$ & & Discouraged \\
\hline & Mulligan taping & & \\
\hline & McConnell taping & & \\
\hline \multirow{4}{*}{$\begin{array}{l}\text { Myofascial Trigger Points } \\
\text { of the Cervical Region } \\
\text { (Upper Trapezius) }\end{array}$} & Rigid taping & & \\
\hline & $\begin{array}{l}\text { Kinesio taping } \\
{[171-179]}\end{array}$ & Equivocal & \\
\hline & Mulligan taping & & \\
\hline & McConnell taping & & \\
\hline \multirow{4}{*}{$\begin{array}{l}\text { Whiplash-associated neck } \\
\text { pain }\end{array}$} & Rigid taping & & \\
\hline & Kinesio taping [180] & Equivocal & \\
\hline & Mulligan taping & & \\
\hline & McConnell taping & & \\
\hline \multirow{4}{*}{$\begin{array}{c}\text { Temporomandibular Joint } \\
\text { Dysfunction }\end{array}$} & Rigid taping & & \\
\hline & $\begin{array}{l}\text { Kinesio taping } \\
{[181-184]}\end{array}$ & Equivocal & \\
\hline & Mulligan taping & & \\
\hline & McConnell taping & & \\
\hline
\end{tabular}

- There is moderate evidence that the use of KT in the treatment of pain and disability for carpal tunnel syndrome is equivocal.

de Quervain's syndrome Evidence summary (Table 5)

- There is promising weak evidence that $\mathrm{KT}$ provides benefits to improve pain or swelling in the treatment of de Quervain's syndrome.

Wrist pain Evidence summary (Table 5)

- There is promising weak evidence that rigid tape provides benefit to improve pain and function in the treatment of dorsal wrist pain.
Osteoarthritis (OA) of the Proximal Interphalangeal Joint

\section{Evidence summary (Table 5)}

- There is moderate evidence that $\mathrm{KT}$ to improve pain or functional improvement in the treatment of OA of the proximal interphalangeal joint is equivocal.

\section{Conditions of the spine}

Of the 41 SRs, six (14.6\%) were related to spinal conditions with overall AMSTAR scores that ranged between 4 to 8 . Of the 127 RCTs, 49 (38.6\%) were related to spinal conditions including temporomandibular joint dysfunction and pain with overall PEDRO scores that ranged between 3 to 9 . Eleven conditions of the lower 
Table 7 Not Otherwise Classified conditions interpretation of the evidence

\begin{tabular}{|l|l|l|l|l|}
\hline Conditions & Intervention & \multicolumn{2}{|l|}{ Quality of Evidence } \\
\hline \multirow{5}{*}{ Myofascial pain syndrome } & & Weak & Moderate & Strong \\
\hline & Rigid taping & & & \\
\cline { 2 - 5 } & $\begin{array}{l}\text { Kinesio taping [186, } \\
\text { 187] }\end{array}$ & Unclear & & \\
\cline { 2 - 5 } & Mulligan taping & & & \\
\hline & McConnell taping & & & \\
\hline \multirow{5}{*}{$\begin{array}{c}\text { Pain secondary to Spinal } \\
\text { Fracture }\end{array}$} & Rigid taping [191] & Promising & & \\
\cline { 2 - 6 } & Kinesio taping & & & \\
\cline { 2 - 6 } & Mulligan taping & & & \\
\cline { 2 - 6 } & McConnell taping & & & \\
\hline
\end{tabular}

extremity were identified and evaluated for taping procedures.

\section{Lumbar spine}

There were five SRs that included conditions related to the lumbar spine (Appendix 1 File: Appendix 1G) [131135]. There were twenty-three RCTs related to conditions of the lumbar spine and abdominal wall, with all but one assessing KT (Appendix 2 File: Appendix 2G). One addressed KT for acute low back pain [136], two investigated $\mathrm{KT}$ for back pain in the setting of lumbar disc herniation [137, 138], two investigated KT for pregnancy related low back pain [139, 140], one RCT investigated postpartum diastasis recti abdominis [141], and sixteen investigated KT for chronic low back pain, [142-157]. One study evaluated rigid taping for sacroiliac joint dysfunction [158]. The overall PEDro scores ranged from 3 to 9 .

\section{Acute low Back pain Evidence summary (Table 6)}

- There is moderate quality evidence that KT provides adjunctive benefit to minimal care for pain control for the treatment of acute low back pain.

\section{Lumbar disc herniation Evidence summary (Table 6)}

- There is moderate evidence that the inclusion of KT in the treatment plan of lumbar disc herniation is equivocal.
Pregnancy-related low Back pain Evidence summary (Table 6)

- There is moderate evidence that $\mathrm{KT}$ is beneficial for improving pain and disability for the treatment of pregnancy-related low back pain.

Diastasis recti abdominis Evidence summary (Table 6)

- There is moderate evidence that $\mathrm{KT}$ is beneficial for improving pain and function for the treatment of diastasis recti abdominis.

Chronic low Back pain Evidence summary (Table 6)

- There is strong evidence that KT improves pain and disability in patients with chronic non-specific low back pain.

Sacroiliac joint dysfunction Evidence summary (Table 6)

- There is weak quality evidence that rigid tape is superior to no treatment for pain and function for the treatment of sacroiliac joint dysfunction.

\section{Thoracic spine}

There were no SRs related to the thoracic spine identified. There were two RCTs that evaluated KT for the treatment of pain and function secondary to osteoporotic thoracic kyphosis [159, 160] (Appendix 2 File: Appendix $2 \mathrm{H})$ with PEDro scores ranging from 6 to 7 . There were 
no RCTs that studied rigid taping, Mulligan taping or $\mathrm{Mc}-\mathrm{T}$ in relation to conditions of the thoracic spine.

\section{Evidence summary (Table 6)}

- There is moderate evidence that KT alone or as part of multimodal rehabilitation is equivocal in the treatment of pain and kyphotic angle in cases of postmenopausal osteoporosis.

\section{Cervical spine}

There was one SR [135] that included conditions related to the cervical spine with an AMSTAR rating of 8 (Appendix 1 File: Appendix 1G). There were twenty RCTs related to the cervical spine that assessed $\mathrm{KT}$, with overall PEDro scores ranging from 4 to 8 (Appendix 2 File: Appendix 2I). Ten RCTs pertained to mechanical or non-specific neck pain [161-170], nine RCTs pertained to trigger points or pain of the upper trapezius [171179], and one RCT investigated whiplash associated neck pain [180]. There were no RCTs that studied rigid taping, Mulligan taping or Mc- $\mathrm{T}$ in relation to conditions of the cervical spine.

\section{Mechanical neck pain Evidence summary (Table 6)}

- There is strong evidence that KT for mechanical neck pain is discouraged.

Upper trapezius pain (myofascial trigger points) Evidence summary (Table 6)

- There is moderate evidence that the inclusion of KT in the treatment plan of upper trapezius pain is equivocal.

Whiplash associated neck pain Evidence summary (Table 6)

- There is moderate evidence that the inclusion of KT in the treatment plan of whiplash associated neck pain is equivocal.

\section{Temporomandibular joint}

There were no SRs related to the temporomandibular joint identified. There were four RCTs related to the treatment of temporomandibular joint dysfunction with KT [181-184] (Appendix 2 File: Appendix 2J). The overall PEDro scores ranged from 4 to 5 . There were no RCTs that studied rigid taping, Mulligan taping or Mc-T in relation to conditions of the temporomandibular joint.

Temporomandibular joint dysfunction Evidence summary (Table 6)
- There is moderate evidence that KT is not superior in the treatment of pain and disability compared to occlusal splint, ischemic compression or exercise in people with temporomandibular joint dysfunction.

\section{Conditions not elsewhere classified Myofascial pain syndrome}

There was one SR assessing KT for the management of myofascial pain syndrome (Appendix 1 File: Appendix $1 \mathrm{H})$ with an AMSTAR score of 3 [185]. There were two RCTs that investigated taping in the management of myofascial pain syndrome $[186,187]$ with PEDro scores that ranged from 3 to 5 (Appendix 2 File: Appendix 2K).

\section{Myofascial pain syndrome}

Evidence summary (Table 7)

- There is weak evidence that KT is not beneficial for pain and function in patients with myofascial pain syndrome.

\section{Other musculoskeletal conditions}

There were three systematic reviews that could not be classified otherwise, yet met our inclusion criteria (Appendix 1I). One SR, with an AMSTAR of 7, evaluated elastic bandages for orthopedic and sports injuries [189]. Another SR, with an AMSTAR of 9, evaluated KT for chronic musculoskeletal pain [190]. One SR, with an AMSTAR 9 assessed the effects of KT for musculoskeletal conditions following intervention after a week [191]. There was one RCT that investigated rigid taping for the management of pain secondary to an active osteoporotic vertebral compression fracture of the thoracic or lumbar spine [188] with a PEDro score of 6 (Appendix 2 File: Appendix 2K).

Pain Secondary to Osteoporotic Vertebral Compression Fracture

\section{Evidence summary (Table 7)}

- There is weak evidence that rigid taping may be beneficial for pain and function in people with active osteoporotic compression fractures.

\section{Discussion}

An evidence map is a tool to identify research gaps and clarify future research agendas, while presenting a userfriendly assessment of the evidence for clinicians as well as researchers [24]. As opposed to systematic reviews, evidence maps do not require a narrow question in a PICO format (population, intervention, comparison and outcome). While using a PICO format can be advantageous, it limited previous SRs to specific conditions in certain body regions or to a particular brand of tape. 
However, the use of an evidence map provides greater flexibility to review the entire body of taping literature. The unique contribution of this evidence map is that it provides a single summary source for all types of taping for all body regions related to a variety of different musculoskeletal conditions. Additionally, this evidence map helps to identify research gaps, and clarify conditions with research surplus. The final unique contribution of this evidence map is the concise clinician-friendly guide or "map" to the reviewed evidence related to taping of musculoskeletal conditions (Tables 4, 5, 6 and 7).

The results of this evidence map show that taping for musculoskeletal conditions is extensively used in clinical and research settings. With respect to SRs, we identified a wide heterogeneity in the populations studied, inclusion and exclusion criteria, taping methods, and outcome measures, resulting in a wide range of conclusions. This heterogeneity did not allow us to pool data or conduct a meta-analysis, making it difficult to provide broad generalizations about the effectiveness of taping on musculoskeletal conditions, based upon the information provided by these SRs.

With respect to the RCTs that we reviewed, the methodological rigor generally ranged from moderate to strong. The RCTs most commonly involved patients with spinal conditions, and KT was the type of tape most commonly studied (90/127 of RCTs), while the least common was Mulligan taping (2/127 of RCTs). Many RCTs used designs that included mixtures of treatment methods such as taping in combination with manual therapy or exercise. These multimodal interventions made it very difficult to parse out the main treatment effect due to taping alone, compared to global treatment effect that came from the combination of other therapeutic methods. However, it is promising that a majority of studies incorporated validate region-specific outcome assessments.

Several studies compared 'placebo' taping with 'real' taping, which was intended to control for the effects of contact with the clinician, but the number of studies that used this placebo-matched design was limited and had inherent methodological shortcomings. Sham taping and soft tissue therapies, as controls, are possibly inadequate options. Since most of the theorized benefits from taping is neurobiological, both controls will stimulate the same proprioceptive receptors that taping intervention methods are proposed to influence [10, 12, 21, 33]. Taping techniques have also been suggested to exert a mechanical effect on joint alignment and tracking, however, studies have not supported this therapeutic mechanism [31]. Theoretical mechanistic underpinnings for elastic and non-elastic taping strategies for musculoskeletal conditions are still under investigation [7, 192]. There is a similar conundrum in the acupuncture literature, questioning if sham or placebo acupuncture are in fact physiologically inert controls [193, 194]. A more adequate taping control would be methods that do not involve direct stimulation of these receptors, however, such methods are still under development [152].

It is important for clinicians to recognize the large variation in the scientific quality of taping research. This should be a warning to exercise caution when translating these results into clinical practice. Whenever a study of a taping method was found to provide no superior results to another rehabilitation intervention, we were keen on informing field clinicians that using the tape is equivocal. It should be noted that of the twenty five conditions evaluated, the effectiveness of KT was equivocal in most cases and one condition had a strong preponderance of evidence discouraging the use of KT for care. We suggest the use of KT be considered through shared decision making based on clinician experience and patient preference.

\section{Limitations}

One limitation of this evidence map is the absence of a meta-analysis, which was not feasible due to the large heterogeneity in the patient populations (e.g. age groups, chronicity, athletic, geriatric, etc.), interventions (e.g. taping alone vs. multi-modal intervention), and research designs (e.g. incorporate blinding procedures, address placebo and sham concerns) of the included studies. Another limitation is that our results were derived only from studies that were published in English. However, only $4(4.5 \%)$ of the SRs were excluded due to language from our search results which was Dutch, Persian, and Spanish.

\section{Recommendations for future research}

Future research should consider the exploration of taping methods for musculoskeletal conditions related to the hip, elbow, wrist, hand and temporomandibular joints as there is a dearth of taping literature associated with these areas of the body. Also, future research should consider the inclusion of an adequate control or a placebo group, in order to delineate the clinical effect of taping from natural history, regression to the mean, or treatment expectation. Additionally, future research should consider isolating the clinical effectiveness of taping alone, separate and distinct from the many other cointerventions that are typically combined with taping (e.g. taping alone vs. rehab vs. taping plus rehab, or taping alone vs. joint manipulation vs. joint manipulation plus taping). Moreover, future research should not focus only on the immediate post-treatment effects of taping but also capture effectiveness data from outcomes derived from longer post-treatment follow-up periods. Finally, future research should consider comparative 
effectiveness designs, in which different types of taping methods (e.g. rigid taping versus KT) are compared with one another, as this would provide more clinically relevant information about the choice of taping strategies and may potentially reveal subgroup characteristics for treatment classification [195-197].

\section{Conclusion}

The goal of this evidence map was to summarize and organize the current evidence on taping for musculoskeletal conditions for all regions of the body. Our results provide a clinician-friendly tool to assist with interpretation of the current state of the evidence regarding the effectiveness of taping for musculoskeletal conditions.

\section{Abbreviations}

AMSTAR: A MeaSurement Tool to Assess systematic Reviews; CINA $\mathrm{HL}$ : Cumulative Index to Nursing and Allied Health Literature; KT: Kinesio tape; Mc-T: McConnell Taping; OA: Osteoarthritis; PFPS: Patellofemoral Pain Syndrome; PEDro: Physiotherapy Evidence Database; RCT: Randomized controlled trial; SIS: Subacromial Impingement Syndrome; SR: Systematic review

\section{Acknowledgements}

The origination of this project was an offshoot of Dr. Polakowski's honors thesis to fulfill the requirements of her Bachelors of Philosophy degree at the University of Pittsburgh.

\section{Authors' note}

The views expressed in this article are those of the authors and do not reflect the official policy or position of the Department of Veterans Affairs, or the United States Government.

\section{Systematic review registration}

The systematic review protocol was registered with PROSPERO (CRD42019122857).

\section{Authors' contributions}

Concept/idea/research design: MS. Writing: MA, ZC, EP, MS. Data acquisition: MA, ZC, EP. Data analysis and interpretation: MA, ZC, KM, MS. Consultation (including review of manuscript before submitting): MA, ZC, KM, MS, EP. The authors read and approved the final manuscript.

\section{Funding}

The authors declare that they have no funding to report for this project.

\section{Availability of data and materials}

All data generated or analysed during this study are included in this published article and its supplementary information files.

\section{Ethics approval and consent to participate}

Not applicable

\section{Consent for publication}

Not applicable.

\section{Competing interests}

The authors declare that they have no competing interests.

\section{Author details}

'Physical Medicine \& Rehabilitation Services, Butler VA Healthcare System, 353 N. Duffy Road, Butler, Pennsylvania, USA. ²Division of Physical Therapy, School of Medicine, West Virginia University, Morgantown, West Virginia, USA. ${ }^{3}$ Department of Physical Therapy, King Fahad Specialist Hospital, Dammam, Saudi Arabia. ${ }^{4}$ Private Practice, Independence Physical Therapy, Mystic, Connecticut, USA. ${ }^{5}$ VA Pittsburgh Healthcare System, Pittsburgh,
Pennsylvania, USA. ${ }^{6}$ Department of Physical Therapy, School of Health and Rehabilitation Sciences, University of Pittsburgh, Pittsburgh, Pennsylvania, USA.

Received: 20 February 2020 Accepted: 12 July 2020

Published online: 15 September 2020

\section{Supplementary information}

Supplementary information accompanies this paper at https://doi.org/10. 1186/s12998-020-00337-2.

Additional file 1: Appendix 1. Systematic review extraction tables organized by body region.

Additional file 2: Appendix 2. Randomized controlled trail extraction tables organized by body region.

\section{Author details}

Supplementary information accompanies this paper at https://doi.org/10. 1186/s12998-020-00337-2.'Physical Medicine \& Rehabilitation Services, Butler VA Healthcare System, 353 N. Duffy Road, Butler, Pennsylvania, USA. ${ }^{2}$ Division of Physical Therapy, School of Medicine, West Virginia University, Morgantown, West Virginia, USA. ${ }^{3}$ Department of Physical Therapy, King Fahad Specialist Hospital, Dammam, Saudi Arabia. ${ }^{4}$ Private Practice, Independence Physical Therapy, Mystic, Connecticut, USA. ${ }^{5}$ VA Pittsburgh Healthcare System, Pittsburgh, Pennsylvania, USA. ${ }^{6}$ Department of Physical Therapy, School of Health and Rehabilitation Sciences, University of Pittsburgh, Pittsburgh, Pennsylvania, USA.

Received: 20 February 2020 Accepted: 12 July 2020

Published online: 15 September 2020

\section{References}

1. United States Bone and Joint Initiative. The burden of musculoskeletal diseases in the United States (BMUS). 4th ed. Rosemont. Available at http:// www.boneandjointburden.org. Accessed on 1 Feb 2020.

2. Collaborators GDallaP. Global, regional, and national incidence, prevalence, and years lived with disability for 328 diseases and injuries for 195 countries, 1990-2016: a systematic analysis for the global burden of disease study 2016. Lancet. 2017;390(10100):1211-59.

3. Cross M, Smith E, Hoy D, et al. The global burden of hip and knee osteoarthritis: estimates from the global burden of disease 2010 study. Ann Rheum Dis. 2014;73(7):1323-30

4. Smith E, Hoy DG, Cross M, et al. The global burden of other musculoskeletal disorders: estimates from the global burden of disease 2010 study. Ann Rheum Dis. 2014;73(8):1462-9.

5. Simon JE. Study of the comparative effectiveness of ankle taping and ankle wrapping on the prevention of ankle injuries. J Nat Athl Trainers Assoc. 1969:4:6-7.

6. Constantinou M, Brown M. Therapeutic taping for musculoskeletal conditions. Chatswood: Elsevier Australia; 2010.

7. Dizon JM, Reyes JJ. A systematic review on the effectiveness of external ankle supports in the prevention of inversion ankle sprains among elite and recreational players. J Sci Med Sport. 2010;13(3):309-17.

8. Williams S, Whatman C, Hume PA, Sheerin K. Kinesio taping in treatment and prevention of sports injuries: a meta-analysis of the evidence for its effectiveness. Sports Med. 2012;42(2):153-64.

9. Grant ME, Steffen K, Glasgow P, Phillips N, Booth L, Galligan M. The role of sports physiotherapy at the London 2012 Olympic games. Br J Sports Med. 2014;48(1):63-70.

10. Lewis M. Comprehensive manual of taping, wrapping, and protective devices. 5th edition. Ed. Urbana: Sagamore Pub; 2017.

11. About Us. Kinesio Tape. https:/kinesiotaping.com/about/. Accessed 3 Feb 2019.

12. What is the kinesio taping method?. https://kinesiotaping.com/about/whatis-the-kinesio-taping-method/. Accessed 3 Feb 2019.

13. Mostafavifar M, Wertz J, Borchers J. A systematic review of the effectiveness of kinesio taping for musculoskeletal injury. Phys Sportsmed. 2012;40(4):33-40. 
14. Parreira PC, Costa LC, Hespanhol LC, Lopes AD, Costa LO. Current evidence does not support the use of Kinesio taping in clinical practice: a systematic review. J Physiother. 2014;60(1):31-9.

15. Kalron A, Bar-Sela S. A systematic review of the effectiveness of Kinesio taping--fact or fashion? Eur J Phys Rehabil Med. 2013;49(5):699-709.

16. Morris $D$, Jones $D$, Ryan $H$, Ryan CG. The clinical effects of Kinesio ${ }^{\circledR}$ Tex taping: a systematic review. Physiother Theory Pract. 2013;29(4):259-70.

17. Montalvo AM, Cara EL, Myer GD. Effect of kinesiology taping on pain in individuals with musculoskeletal injuries: systematic review and metaanalysis. Phys Sportsmed. 2014;42(2):48-57.

18. Chang WD, Chen FC, Lee CL, Lin HY, Lai PT. Effects of Kinesio taping versus McConnell taping for patellofemoral pain syndrome: a systematic review and meta-analysis. Evid Based Complement Alternat Med. 2015;2015:471208.

19. Campolo M, Babu J, Dmochowska K, Scariah S, Varughese J. A comparison of two taping techniques (kinesio and mcconnell) and their effect on anterior knee pain during functional activities. Int J Sports Phys Ther. 2013;8(2):105-10.

20. Lan TY, Lin WP, Jiang CC, Chiang $H$. Immediate effect and predictors of effectiveness of taping for patellofemoral pain syndrome: a prospective cohort study. Am J Sports Med. 2010;38(8):1626-30.

21. Callaghan MJ, Selfe J, McHenry A, Oldham JA. Effects of patellar taping on knee joint proprioception in patients with patellofemoral pain syndrome. Man Ther. 2008;13(3):192-9.

22. Vicenzino B, Paungmali A, Teys P. Mulligan's mobilization-with-movement, positional faults and pain relief: current concepts from a critical review of literature. Man Ther. 2007;12(2):98-108.

23. Hopper D, Samsson K, Hulenik T, Ng C, Hall T, Robinson K. The influence of mulligan ankle taping during balance performance in subjects with unilateral chronic ankle instability. Phys Ther Sport. 2009;10(4):125-30.

24. Miake-Lye I, Hempel S, Shanman R, Shekelle P. What is evidence map? A systematic review of published evidence maps and their definitions, methods, and products. Syst Rev. 2016;5:28.

25. Olivo SA, Macedo LG, Gadotti IC, Fuentes J, Stanton T, Magee DJ. Scales to assess the quality of randomized controlled trials: a systematic review. Phys Ther. 2008:88(2):156-75.

26. Moseley AM, Herbert RD, Sherrington C, Maher CG. Evidence for physiotherapy practice: a survey of the physiotherapy evidence database (PEDro). Aust J Physiother. 2002;48(1):43-9.

27. Barton C, Balachandar V, Lack S, Morrissey D. Patellar taping for patellofemoral pain: a systematic review and meta-analysis to evaluate clinical outcomes and biomechanical mechanisms. Br J Sports Med. 2014;48(6):417-24.

28. Bolgla LA, Boling MC. An update for the conservative management of patellofemoral pain syndrome: a systematic review of the literature from 2000 to 2010. Int J Sports Phys Ther. 2011;6(2):112-25.

29. Callaghan MJ, Selfe J. Patellar taping for patellofemoral pain syndrome in adults. Cochrane Database Syst Rev. 2012;4:CD006717.

30. Collins NJ, Bisset LM, Crossley KM, Vicenzino B. Efficacy of nonsurgical interventions for anterior knee pain: systematic review and meta-analysis of randomized trials. Sports Med. 2012;42(1):31-49.

31. Leibbrandt DC, Louw QA. The use of McConnell taping to correct abnormal biomechanics and muscle activation patterns in subjects with anterior knee pain: a systematic review. J Phys Ther Sci. 2015;27(7):2395-404.

32. Logan CA, Bhashyam AR, Tisosky AJ, et al. Systematic review of the effect of taping techniques on patellofemoral pain syndrome. Sports Health. 2017; 9(5):456-61.

33. Ouyang JH, Chang KH, Hsu WY, Cho YT, Liou TH, Lin YN. Non-elastic taping, but not elastic taping, provides benefits for patients with knee osteoarthritis: systematic review and meta-analysis. Clin Rehabil. 2018;32(1):3-17

34. Li X, Zhou X, Liu H, Chen N, Liang J, Yang X, et al. Effects of elastic therapeutic taping on knee osteoarthritis: a systematic review and metaanalysis. Aging Dis. 2018;9(2):296-308.

35. Akbaş E, Atay AO, Yüksel I. The effects of additional kinesio taping over exercise in the treatment of patellofemoral pain syndrome. Acta Orthop Traumatol Turc. 2011:45(5):335-41.

36. Clark DI, Downing N, Mitchell J, Coulson L, Syzpryt EP, Doherty M. Physiotherapy for anterior knee pain: a randomised controlled trial. Ann Rheum Dis. 2000;59(9):700-4.

37. Ghourbanpour A, Talebi GA, Hosseinzadeh S, Janmohammadi N, Taghipour M. Effects of patellar taping on knee pain, functional disability, and patellar alignments in patients with patellofemoral pain syndrome: a randomized clinical trial. J Bodyw Mov Ther. 2018;22(2):493-7.
38. Harrison EL, Sheppard MS. McQuarrie. A randomized controlled trial of physical therapy treatment programs in patellofemoral pain syndrome. Physiother Can. 1999;51(2):93-196.

39. Kowall MG, Kolk G, Nuber GW, Cassisi JE, Stern SH. Patellar taping in the treatment of patellofemoral pain. A prospective randomized study. Am J Sports Med. 1996;24(1):61-6.

40. Mason M, Keays SL, Newcombe PA. The effect of taping, quadriceps strengthening and stretching prescribed separately or combined on patellofemoral pain. Physiother Res Int. 2011;16(2):109-19.

41. Miller J, Westrick R, Diebal A, Marks C, Gerber JP. Immediate effects of lumbopelvic manipulation and lateral gluteal kinesio taping on unilateral patellofemoral pain syndrome: a pilot study. Sports Health. 2013;5(3):214-9.

42. Whittingham M, Palmer S, Macmillan F. Effects of taping on pain and function in patellofemoral pain syndrome: a randomized controlled trial. J Orthop Sports Phys Ther. 2004;34(9):504-10.

43. Aydoğdu O, Sari Z, Yurdalan SU, Polat MG. Clinical outcomes of kinesio taping applied in patients with knee osteoarthritis: a randomized controlled trial. J Back Musculoskelet Rehabil. 2017;30(5):1045-51.

44. Bennell KL, Hinman RS, Metcalf BR, et al. Efficacy of physiotherapy management of knee joint osteoarthritis: a randomised, double blind, placebo controlled trial. Ann Rheum Dis. 2005;64(6):906-12

45. Cushnaghan J, McCarthy C, Dieppe P. Taping the patella medially: a new treatment for osteoarthritis of the knee joint? BMJ. 1994;308(6931):753-5.

46. Dhanakotti S, Samuel RK, Thakar M, Doshi S, Vadsola K. Effects of additional kinesiotaping over the conventional physiotherapy exercise on pain, quadriceps strength and knee functional disability in knee osteoarthritis participants: a randomized controlled study. Int J Health Sci Res. 2016;6(1):221-9.

47. Han JW, Lee DK, Park CB. The immediate effects of taping therapy on knee pain and depression in patients with degenerative arthritis. J Phys Ther Sci. 2018;30(5):704-6.

48. Hinman RS, Crossley KM, McConnell J, Bennell KL. Efficacy of knee tape in the management of osteoarthritis of the knee: blinded randomised controlled trial. BMJ. 2003;327(7407):135.

49. Ibrahim ARI, Atya AM. Kinesio taping versus sensorymotor training for patients with knee osteoarthritis. IJTRR. 2015:4(3):9-14.

50. Kaya Mutlu E, Mustafaoglu R, Birinci T, Razak OA. Does Kinesio taping of the knee improve pain and functionality in patients with knee osteoarthritis?: a randomized controlled clinical trial. Am J Phys Med Rehabil. 2017:96(1):25-33.

51. Kocyigit F, Turkmen MB, Acar $M$, et al. Kinesio taping or sham taping in knee osteoarthritis? A randomized, double-blind, sham-controlled trial. Complement Ther Clin Pract. 2015;21(4):262-7.

52. Malgaonkar PP, Sai KN, Vinod BK, Rizvi SR. Short term effect of Mulligan's mobilization versus kinesio taping on knee pain and disability for osteoarthritis of knee. International J Physiother. 2014;1(4):233-40.

53. Öğüt H, Güler H, Yildizgören MT, Velioğlu O, Turhanoğlu AD. Does kinesiology taping improve muscle strength and function in knee osteoarthritis? A single-blind, randomized and controlled study. Arch Rheumatol. 2018;33(3):335-43.

54. Parekh S, Vaghela N. Immediate effect of taping in physical performance of osteoarthritis of knee joint. Natl J Physiol Pharm Pharmacol. 2018;8(4):570-4.

55. Quilty B, Tucker M, Campbell R, Dieppe P. Physiotherapy, including quadriceps exercises and patellar taping, for knee osteoarthritis with predominant patello-femoral joint involvement: randomized controlled trial. J Rheumatol. 2003:30(6):1311-7.

56. Rinkle H, Santosh M, Ganesh BR. Comparison of mcconnell patellar taping versus mobilisation with movement in chronic knee osteoarthritis: a randomized clinical trial. Indian J Physiother Occup Ther. 2010;4(4):132-6.

57. Sedhom MG. Efficacy of kinesio-taping versus phonophoresis on knee osteoarthritis: an experimental study. Int J Physiother. 2016;3(4):494-9.

58. Sudhesh P. Effect of taping and closed kinetic chain versus traditional approach in osteoarthritis knee. Int J Pharm Bio Sci. 2013;4(4):1156-65.

59. Wageck B, Nunes GS, Bohlen NB, Santos GM, de Noronha M. Kinesio taping does not improve the symptoms or function of older people with knee osteoarthritis: a randomised trial. J Physiother. 2016;62(3):153-8.

60. Rood A, Boons H, Ploegmakers J, van der Stappen W, Koëter S. Tape versus cast for non-operative treatment of primary patellar dislocation: a randomized controlled trial. Arch Orthop Trauma Surg. 2012;132(8):1199-203.

61. Kachanathu SJ, Algarni FS, Nuhmani S, Alenazi AM, Hafez AR, Algarni AD. Functional outcomes of kinesio taping versus standard orthotics in the management of shin splint. J Sports Med Phys Fitness. 2018;58(11):1666-70. 
62. Ardèvol J, Bolíbar I, Belda V, Argilaga S. Treatment of complete rupture of the lateral ligaments of the ankle: a randomized clinical trial comparing cast immobilization with functional treatment. Knee Surg Sports Traumatol Arthrosc. 2002:10(6):371-7.

63. Johannes EJ, Sukul DM, Spruit PJ, Putters JL. Controlled trial of a semi-rigid bandage ('Scotchrap') in patients with ankle ligament lesions. Curr Med Res Opin. 1993;13(3):154-62.

64. Lardenoye S, Theunissen E, Cleffken B, Brink PR, de Bie RA, Poeze M. The effect of taping versus semi-rigid bracing on patient outcome and satisfaction in ankle sprains: a prospective, randomized controlled trial. BMC Musculoskelet Disord. 2012;13:81.

65. Mickel TJ, Bottoni CR, Tsuji G, Chang K, Baum L, Tokushige KA. Prophylactic bracing versus taping for the prevention of ankle sprains in high school athletes: a prospective, randomized trial. J Foot Ankle Surg. 2006:45(6):360-5.

66. Specchiulli F, Cofano RE. A comparison of surgical and conservative treatment in ankle ligament tears. Orthopedics. 2001;24(7):686-8.

67. van den Bekerom MP, van Kimmenade R, Sierevelt IN, et al. Randomized comparison of tape versus semi-rigid and versus lace-up ankle support in the treatment of acute lateral ankle ligament injury. Knee Surg Sports Traumatol Arthrosc. 2016;24(4):978-84.

68. Nunes GS, Vargas VZ, Wageck B, Hauphental DP, da Luz CM, de Noronha M Kinesio taping does not decrease swelling in acute, lateral ankle sprain of athletes: a randomised trial. J Physiother. 2015;61(1):28-33.

69. Abd El Salam MS, Abd Elhafz YN. Low-dye taping versus medial arch support in managing pain and pain-related disability in patients with plantar fasciitis. Foot Ankle Spec. 2011;4(2):86-91.

70. Hyland MR, Webber-Gaffney A, Cohen L, Lichtman PT. Randomized controlled trial of calcaneal taping, sham taping, and plantar fascia stretching for the short-term management of plantar heel pain. J Orthop Sports Phys Ther. 2006;36(6):364-71.

71. Lynch DM, Goforth WP, Martin JE, Odom RD, Preece CK, Kotter MW. Conservative treatment of plantar fasciitis. A prospective study. J Am Podiatr Med Assoc. 1998;88(8):375-80.

72. Radford JA, Landorf KB, Buchbinder R, Cook C. Effectiveness of low-dye taping for the short-term treatment of plantar heel pain: a randomised trial. BMC Musculoskelet Disord. 2006;7:64.

73. Vishal B, Santosh M, Ganesh BR. Effectiveness of plantar fasciitis taping and calcaneal taping in plantar heel pain: a randomized clinical trial. Indian J Physiother Occup Ther. 2010;4(3):86-90.

74. Tsai C, Chang W, Lee J. Effects of short-term treatment with kinesiotaping for plantar fasciitis. J Musculoskelet Pain. 2010;18(1):71-80

75. Mehta S, Basu S, Palekar TJ, Dave N. Effect of kinesio taping versus mulligan taping in treatment of heel pain. Int J Pharm Bio Sci. 2017;8(3):377-86.

76. Kemler E, van de Port I, Backx F, van Dijk CN. A systematic review on the treatment of acute ankle sprain: brace versus other functional treatment types. Sports Med. 2011;41(3):185-97.

77. Raymond J, Nicholson LL, Hiller CE, Refshauge KM. The effect of ankle taping or bracing on proprioception in functional ankle instability: a systematic review and meta-analysis. J Sci Med Sport. 2012;15(5):386-92.

78. Seah R, Mani-Babu S. Managing ankle sprains in primary care: what is best practice? A systematic review of the last 10 years of evidence. Br Med Bull. 2011;97:105-35

79. Wang Y, Gu Y, Chen J, Luo W, He W, Han Z, et al. Kinesio taping is superior to other taping methods in ankle functional performance improvement: a systematic review and meta-analysis. Clin Rehabil. 2018; 32(11):1472-81.

80. Wilson B, Bialocerkowski A. The effects of Kinesiotape applied to the latera aspect of the ankle: relevance to ankle sprains--a systematic review. PLoS One. 2015;10(6):e0124214.

81. Yu H, Randhawa K, Côté P. Optima collaboration. The effectiveness of physical agents for lower-limb soft tissue injuries: a systematic review. J Orthop Sports Phys Ther. 2016;46(7):523-54.

82. Podolsky R, Kalichman L. Taping for plantar fasciitis. J Back Musculoskelet Rehabil. 2015;28(1):1-6.

83. Salvioli S, Guidi M, Marcotulli G. The effectiveness of conservative, nonpharmacological treatment, of plantar heel pain: a systematic review with meta-analysis. Foot (Edinb). 2017;33:57-67.

84. van de Water AT, Speksnijder CM. Efficacy of taping for the treatment of plantar fasciosis: a systematic review of controlled trials. J Am Podiatr Med Assoc. 2010;100(1):41-51.
85. Cheung RT, Chung RC, Ng GY. Efficacies of different external controls for excessive foot pronation: a meta-analysis. Br J Sports Med. 2011; 45(9):743-51.

86. Franettovich M, Chapman A, Blanch P, Vicenzino B. A physiological and psychological basis for anti-pronation taping from a critical review of the literature. Sports Med. 2008:38(8):617-31.

87. Radford JA, Burns J, Buchbinder R, Landorf KB, Cook C. The effect of lowdye taping on kinematic, kinetic, and electromyographic variables: a systematic review. J Orthop Sports Phys Ther. 2006;36(4):232-41.

88. Desjardins-Charbonneau A, Roy JS, Dionne CE, Desmeules F. The efficacy of taping for rotator cuff tendinopathy: a systematic review and meta-analysis. Int J Sports Phys Ther. 2015;10(4):420-33.

89. Dong W, Goost H, Lin XB, et al. Treatments for shoulder impingement syndrome: a PRISMA systematic review and network meta-analysis. Medicine (Baltimore). 2015;94(10):e510.

90. Haik MN, Alburquerque-Sendín F, Moreira RF, Pires ED, Camargo PR. Effectiveness of physical therapy treatment of clearly defined subacromial pain: a systematic review of randomised controlled trials. Br J Sports Med. 2016;50(18):1124-34.

91. Lai CC, Chen SY, Yang JL, Lin JJ. Effectiveness of stretching exercise versus kinesiotaping in improving length of the pectoralis minor: a systematic review and network meta-analysis. Phys Ther Sport. 2019;40:19-26.

92. Reijneveld EA, Noten S, Michener LA, Cools A, Struyf F. Clinical outcomes of a scapular-focused treatment in patients with subacromial pain syndrome: a systematic review. Br J Sports Med. 2017;51(5):436-41.

93. Saracoglu I, Emuk Y, Taspinar F. Does taping in addition to physiotherapy improve the outcomes in subacromial impingement syndrome? A systematic review. Physiother Theory Pract. 2018;34(4):251-63.

94. Steuri R, Sattelmayer M, Elsig S, et al. Effectiveness of conservative interventions including exercise, manual therapy and medical management in adults with shoulder impingement: a systematic review and metaanalysis of RCTs. Br J Sports Med. 2017:51(18):1340-7.

95. Yu H, Côté $P$, Shearer HM, et al. Effectiveness of passive physical modalities for shoulder pain: systematic review by the Ontario protocol for traffic injury management collaboration. Phys Ther. 2015;95(3):306-18.

96. Apeldoorn AT, Kamper SJ, Kalter J, Knol DL, van Tulder MW, Ostelo RW. Rigid shoulder taping with physiotherapy in patients with subacromial pain syndrome: a randomized controlled trial. J Rehabil Med. 2017;49(4): 347-53.

97. Kumar N, Nehru A, Rajalakshmi D. Effect of taping as a component of conservative treatment for subacromial impingement syndrome. Health. 2012;4:237-41.

98. Miller P, Osmotherly P. Does scapula taping facilitate recovery for shoulder impingement symptoms? A pilot randomized controlled trial. J Man Manip Ther. 2009;17(1):E6-E13.

99. Devereaux M, Velanoski KQ, Pennings A, Elmaraghy A. Short-term effectiveness of precut kinesiology tape versus an NSAID as adjuvant treatment to exercise for subacromial impingement: a randomized controlled trial. Clin J Sport Med. 2016;26(1):24-32.

100. Djordjevic OC, Vukicevic D, Katunac L, Jovic S. Mobilization with movement and kinesiotaping compared with a supervised exercise program for painful shoulder: results of a clinical trial. J Manipulative Physiol Ther. 2012;35(6): 454-63.

101. Frassanito P, Cavalieri C, Maestri R, Felicetti G. Effectiveness of extracorporeal shock wave therapy and kinesio taping in calcific tendinopathy of the shoulder: a randomized controlled trial. Eur J Phys Rehabil Med. 2018;54(3): 333-40.

102. Göksu H, Tuncay F, Borman P. The comparative efficacy of kinesio taping and local injection therapy in patients with subacromial impingement syndrome. Acta Orthop Traumatol Turc. 2016;50(5):483-8.

103. Kaya E, Zinnuroglu M, Tugcu I. Kinesio taping compared to physical therapy modalities for the treatment of shoulder impingement syndrome. Clin Rheumatol. 2011;30(2):201-7.

104. Kaya DO, Baltaci G, Toprak U, Atay AO. The clinical and sonographic effects of kinesiotaping and exercise in comparison with manual therapy and exercise for patients with subacromial impingement syndrome: a preliminary trial. J Manipulative Physiol Ther. 2014;37(6):422-32.

105. Kocyigit F, Acar M, Turkmen MB, Kose T, Guldane N, Kuyucu E. Kinesio taping or just taping in shoulder subacromial impingement syndrome? A randomized, double-blind, placebo-controlled trial. Physiother Theory Pract. 2016;32(7):501-8. 
106. Kul A, Ugur M. Comparison of the efficacy of conventional physical therapy modalities and Kinesio taping treatments in shoulder impingement syndrome. Eur J Med. 2019;51(2):139-44.

107. Miccinilli S, Bravi M, Morrone M, Santacaterina F, Stellato L, Bressi F, et al. A triple application of Kinesio taping supports rehabilitation program for rotator cuff tendinopathy: a randomized controlled trial. Ortop Traumatol Rehabil. 2018;20(6):499-505.

108. Pekyavas NO, Baltaci G. Short-term effects of high-intensity laser therapy, manual therapy, and Kinesio taping in patients with subacromial impingement syndrome. Lasers Med Sci. 2016;31(6):1133-41.

109. Shakeri H, Keshavarz R, Arab AM, Ebrahimi I. Clinical effectiveness of kinesiological taping on pain and pain-free shoulder range of motion in patients with shoulder impingement syndrome: a randomized, double blinded, placebo-controlled trial. Int J Sports Phys Ther. 2013;8(6):800-10.

110. Shakeri $H$, Keshavarz R, Aram AM, Ebrahimi I. A randomized clinical trial of Kinesio-taping on DASH in patients with subacromial impingement syndrome. J Nov Physiother. 2013;3(4):1000169.

111. Şimşek HH, Balki S, Keklik SS, Öztürk H, Elden H. Does Kinesio taping in addition to exercise therapy improve the outcomes in subacromial impingement syndrome? A randomized, double-blind, controlled clinical trial. Acta Orthop Traumatol Turc. 2013;47(2):104-10.

112. Subaşı V, Çakır T, Arıca Z, et al. Comparison of efficacy of kinesiological taping and subacromial injection therapy in subacromial impingement syndrome. Clin Rheumatol. 2016;35(3):741-6.

113. Thelen MD, Dauber JA, Stoneman PD. The clinical efficacy of kinesio tape for shoulder pain: a randomized, double-blinded, clinical trial. J Orthop Sports Phys Ther. 2008;38(7):389-95.

114. Teys P, Bisset L, Collins N, Coombes B, Vicenzino B. One-week time course of the effects of Mulligan's mobilisation with movement and taping in painful shoulders. Man Ther. 2013;18(5):372-7.

115. Bhambani S, Mitra M, Kaur A. Effectiveness of Kinesiotaping along with conventional physiotherapy for patients with tennis elbow. Indian J Physiother Occup Ther. 2016;10(3):18-22.

116. Desai BD, Babu VK, Kumar SD, Asha D. Effectiveness of medial to lateral taping with exercise programmer in subjects with lateral epicondylitis. Int J Physiother. 2014;1(2):83-90.

117. Kachanathu SJ, Miglani S, Grover D, Zakaria AR. Forearm band versus elbow taping: as a management of lateral epicondylitis. J Musculoskelet Res. 2013; 16(1):1350003

118. Eraslan L, Yuce D, Erbilici A, Baltaci G. Does Kinesiotaping improve pain and functionality in patients with newly diagnosed lateral epicondylitis? Knee Surg Sports Traumatol Arthrosc. 2018;26(3):938-45.

119. Giray E, Karali-Bingul D, Akyuz G. The effectiveness of Kinesiotaping, sham taping or exercises only in lateral epicondylitis treatment: a randomized controlled study. PM R. 2019;11(7):681-93.

120. Shakeri H, Soleimanifar M, Arab AM, Hamneshin BS. The effects of KinesioTape on the treatment of lateral epicondylitis. J Hand Ther. 2018; 31(1):35-41.

121. Wegener RL, Brown T, O'Brien L. A randomized controlled trial of comparative effectiveness of elastic therapeutic tape, sham tape or eccentric exercises alone for lateral elbow tendinosis. Hand Therapy. 2016;21(4):131-9.

122. Aktürk S, Büyükavcı R, Aslan Ö, Ersoy Y. Comparison of splinting and Kinesio taping in the treatment of carpal tunnel syndrome: a prospective randomized study. Clin Rheumatol. 2018;37(9):2465-9.

123. Geler Külcü D, Bursali C, Aktaș I, Bozkurt Alp S, Ünlü Özkan F, Akpinar P. Kinesiotaping as an alternative treatment method for carpal tunnel syndrome. Turk J Med Sci. 2016;46(4):1042-9.

124. Güner A, Altan L, Kasapoğlu AM. The effectiveness of the low-power laser and kinesiotaping in the treatment of carpal tunnel syndrome, a pilot study. Rheumatol Int. 2018;38(5):895-904.

125. Yıldırım P, Dilek B, Sahin E, Gülbahar S, Kızıl R. Ultrasonographic and clinical evaluation of additional contribution of kinesiotaping to tendon and nerve gliding exercises in the treatment of carpal tunnel syndrome. Turk J Med Sci. 2018;48(5):925-32.

126. Homayouni K, Zeynali L, Mianehsaz E. Comparison between kinesio taping and physiotherapy in the treatment of de quervain's disease. J Musculoskelet Res. 2013;16(4):1350019.

127. Kim GS, Weon JH, Kim MH, Koh EK, Jung DY. Effect of weight-bearing wrist movement with carpal-stabilizing taping on pain and range of motion in subjects with dorsal wrist pain: a randomized controlled trial. J Hand Ther. 2020;33(1):25-33
128. Wade RG, Paxman CB, Tucker NC, Southern S. Kinesiology taping reduces the pain of finger osteoarthritis: a pilot single-blinded two-group parallel randomized trial. J Pain Res. 2018;11:1281-8.

129. George CE, Heales LJ, Stanton R, Wintour SA, Kean CO. Sticking to the facts: a systematic review of the effects of therapeutic tape in lateral epicondylalgia. Phys Ther Sport. 2019;40:117-27.

130. D'Angelo K, Sutton D, Côté $P$, et al. The effectiveness of passive physical modalities for the management of soft tissue injuries and neuropathies of the wrist and hand: a systematic review by the Ontario protocol for traffic injury management (OPTIMa) collaboration. J Manipulative Physiol Ther. 2015;38(7):493-506.

131. Li Y, Yin Y, Jia G, Chen H, Yu L, Wu D. Effects of kinesiotape on pain and disability in individuals with chronic low back pain: a systematic review and meta-analysis of randomized controlled trials. Clin Rehabil. 2019;33(4):596-606.

132. Luz Júnior MAD, Almeida MO, Santos RS, Civile VT, Costa LOP. Effectiveness of Kinesio taping in patients with chronic nonspecific low Back pain: a systematic review with meta-analysis. Spine (Phila Pa 1976) 2019;44(1):68-78.

133. Nelson NL. Kinesio taping for chronic low back pain: a systematic review. J Bodyw Mov Ther. 2016;20(3):672-81.

134. Sheng Y, Duan Z, Qu Q, Chen W, Yu B. Kinesio taping in treatment of chronic non-specific low back pain: a systematic review and meta-analysis. J Rehabil Med. 2019;51(10):734-40.

135. Vanti C, Bertozzi L, Gardenghi I, Turoni F, Guccione AA, Pillastrini P. Effect of taping on spinal pain and disability: systematic review and meta-analysis of randomized trials. Phys Ther. 2015;95(4):493-506.

136. Kelle B, Güzel R, Sakallı $H$. The effect of Kinesio taping application for acute non-specific low back pain: a randomized controlled clinical trial. Clin Rehabil. 2016;30(10):997-1003.

137. Grześkowiak M, Krawiecki Z, Łabędź W, Kaczmarczyk J, Lewandowski J, Łochyński D. Short-term effects of Kinesio taping ${ }^{\circledR}$ on Electromyographic characteristics of Paraspinal muscles, pain, and disability in patients with lumbar disk herniation. J Sport Rehabil. 2019;28(5):402-12.

138. Keles BY, Yalcinkaya EY, Gunduz B, Bardak AN, Erhan B. Kinesio taping in patients with lumbar disc herniation: a randomised, controlled, double-blind study. J Back Musculoskelet Rehabil. 2017;30(3):543-50.

139. Kaplan \$̧, Alpayci M, Karaman E, et al. Short-term effects of Kinesio taping in women with pregnancy-related low Back pain: a randomized controlled clinical trial. Med Sci Monit. 2016;22:1297-301.

140. Mohamed EA, El-Shamy FF, Hamed H. Efficacy of kinesiotape on functional disability of women with postnatal back pain: a randomized controlled trial. J Back Musculoskelet Rehabil. 2018;31(1):205-10.

141. Tuttle L, Fasching J, Keller A, Patel M, Saville C, Schlaff R, et al. Noninvasive treatment of postpartum diastasis recti abdominis: a pilot study. J Womens Health Phys Therap. 2018;42(2):65-75.

142. Added MA, Costa LO, de Freitas DG, et al. Kinesio taping does not provide additional benefits in patients with chronic low Back pain who receive exercise and manual therapy: a randomized controlled trial. J Orthop Sports Phys Ther. 2016;46(7):506-13.

143. Al-Shareef AT, Omar MT, Ibrahim AH. Effect of Kinesio taping on pain and functional disability in chronic nonspecific low Back pain: a randomized clinical trial. Spine (Phila Pa 1976). 2016;41(14):E821-8.

144. Araujo AC, do Carmo Silva Parreira $P$, Junior LCH, et al. Medium term effects of kinesio taping in patients with chronic non-specific low back pain: a randomized controlled trial. Physiotherapy. 2018;104(1):149-51.

145. Bae SH, Lee JH, Oh KA, Kim KY. The effects of kinesio taping on potential in chronic low back pain patients anticipatory postural control and cerebral cortex. J Phys Ther Sci. 2013;25(11):1367-71.

146. Castro-Sánchez AM, Lara-Palomo IC, Matarán-Peñarrocha GA, FernándezSánchez M, Sánchez-Labraca N, Arroyo-Morales M. Kinesio taping reduces disability and pain slightly in chronic non-specific low back pain: a randomised trial. J Physiother. 2012;58(2):89-95.

147. Chen SM, Alexander R, Lo SK, Cook J. Effects of functional fascial taping on pain and function in patients with non-specific low back pain: a pilot randomized controlled trial. Clin Rehabil. 2012;26(10):924-33.

148. Elshinnawy $A$, Elrazik $R$, Elatief $E$. The effect of muscle energy techniques versus cross $(X)$ technique Kinesio taping to treat chronic low back dysfunction. Int J Ther Rehabil. 2019;26(2):1-8.

149. Kachanathu SJ, Alenazi AM, Seif HE, Hafez AR, Alroumim MA. Comparison between Kinesio taping and a traditional physical therapy program in treatment of nonspecific low Back pain. J Phys Ther Sci. 2014;26(8):1185-8. 
150. Kamali F, Sinaei E, Taherkhani E. Comparing spinal manipulation with and without Kinesio taping. J Bodyw Mov Ther. 2018;22(2):540-5.

151. Köroğlu F, Çolak TK, Polat MG. The effect of Kinesio ${ }^{\oplus}$ taping on pain, functionality, mobility and endurance in the treatment of chronic low back pain: a randomized controlled study. J Back Musculoskelet Rehabil. 2017; 30(5):1087-93.

152. Luz Junior MA, Sousa MV, Neves LA, et al. Kinesio taping is not better than placebo in reducing pain and disability in patients with chronic non-specific low back pain: a randomized controlled trial. Braz J Phys Ther. 2015;19:482-90.

153. Macedo LB, Richards J, Borges DT, Melo SA, Brasileiro JS. Kinesio taping reduces pain and improves disability in low back pain patients: a randomised controlled trial. Physiotherapy. 2019;105(1):65-75.

154. Paoloni M, Bernetti A, Fratocchi G, et al. Kinesio taping applied to lumbar muscles influences clinical and electromyographic characteristics in chronic low back pain patients. Eur J Phys Rehabil Med. 2011;47(2):237-44.

155. Parreira PCS, Costa LCM, Takahashi R, Hespanol Junior LC, da Luz Junior MA da Silva TM, et al. Kinesio taping to generate skin convolutions is not better than sham taping for people with chronic non-specific low back pain: a randomised trial. J Physiother. 2014;60(2):90-6.

156. Uzunkulaoğlu A, Güneş Aytekin M, Ay S, Ergin S. The effectiveness of Kinesio taping on pain and clinical features in chronic non-specific low back pain: a randomized controlled clinical trial. Turk J Phys Med Rehabil. 2018;64(2):126-32.

157. Velasco-Roldán O, Riquelme I, Ferragut-Garcías A, Heredia-Rizo AM, Rodríguez-Blanco C, Oliva-Pascual-Vaca Á. Immediate and short-term effects of Kinesio taping tightness in mechanical low Back pain: a randomized controlled trial. PM R. 2018;10(1):28-35.

158. Neamat Allah N, Sigward S, Mohamed G, Elhafez S, Emran I. Effect of repeated application of rigid tape on pain and mobility deficits associated with sacroiliac joint dysfunction. J Back Musculoskelet Rehabil. 2019;32(3):487-96.

159. Bautmans I, Van Arken J, Van Mackelenberg M, Mets T. Rehabilitation using manual mobilization for thoracic kyphosis in elderly postmenopausal patients with osteoporosis. J Rehabil Med. 2010;42(2):129-35.

160. Bulut D, Dilek B, Kılınç A, Ellidokuz H, Öncel S. An investigation into the effects of kinesiotaping for posture correction on kyphosis angle, pain, and balance in patients with postmenopausal osteoporosis-associated thoracic kyphosis. Arch Osteoporos. 2019;14(1):89.

161. Dawood RS, Kattabei OM, Nasef SA, Battarjee KA, Abdelraouf OR. Effectiveness of kinesio taping versus cervical traction on mechanical neck dysfunction. Int J Ther Rehabil Res. 2013;2(2):1-5.

162. El-Abd AM, Ibrahim AR, El-Hafez HM. Efficacy of kinesiology tape versus postural correction exercises on neck disability and axioscapular muscles fatigue in mechanical neck dysfunction: a randomized blinded clinical trial. J Bodyw Mov Ther. 2017;21(2):314-21.

163. El-Abd AM, Ibrahim AR, El-Hafez HM. Efficacy of kinesio taping versus postural correction exercises on pain intensity and axioscapular muscles activation in mechanical neck dysfunction: a randomized blinded clinical trial. J Sports Med Phys Fitness. 2017;57(10):1311-7.

164. El-Abd A, Ibrahim A, Elhafez $\mathrm{H}$. Kinesio taping versus postural correction exercises on mechanically triggered neck dysfunction. Int J Ther Rehabil. 2017;24(4):155-62.

165. Kavlak B, Bakar Y, Sari Z. Investigation of the efficacy of different physiotherapy methods for neck pain. J Musculoskelet Pain. 2012;20(4):284-91.

166. Klinic HE, Harput G, Baltaci G. Additional effects of kinesiotaping to mobilization techniques in chronic mechanical neck pain. Turk J of Physiother Rehab. 2015;26(3):107-13.

167. Kim J, Kim S, Shim J, Kim H, Moon S, Lee N, et al. Effects of McKenzie exercise, Kinesio taping, and myofascial release on the forward head posture. J Phys Ther Sci. 2018;30(8):1103-7.

168. Puerma-Castillo MC, García-Ríos MC, Pérez-Gómez ME, Aguilar-Ferrándiz ME, Peralta-Ramírez Ml. Effectiveness of kinesio taping in addition to conventional rehabilitation treatment on pain, cervical range of motion and quality of life in patients with neck pain: a randomized controlled trial. J Back Musculoskelet Rehabil. 2018;31(3):453-64.

169. Saavedra-Hernández M, Castro-Sánchez AM, Arroyo-Morales M, Cleland JA, Lara-Palomo IC, Fernández-de-Las-Peñas C. Short-term effects of kinesio taping versus cervical thrust manipulation in patients with mechanical neck pain: a randomized clinical trial. J Orthop Sports Phys Ther. 2012;42(8):724-30.

170. Sobhani V, Shamsoddini A, Khatibi-Aghda A, Mazloum V, Kia H, Meybodi M. Effectiveness of dry needling, manual therapy, and Kinesio taping ${ }^{\circledast}$ for patients with chronic myofascial neck pain: a single-blind clinical trial. Trauma Mon. 2017;22(6):e39261.

171. Ata $E$, Kösem M, Adiguzel E. Does kinesiotaping increase the efficacy of lidocaine injection in myofascial pain syndrome treatment? A randomized controlled study. J Back Musculoskelet Rehabil. 2019;32(3):471-7.

172. Ay S, Konak HE, Evcik D. The effectiveness of kinesio taping on pain and disability in cervical myofascial pain syndrome. Rev Bras Reumatol. 2017;57:93-9.

173. Azatcam G, Atalay NS, Akkaya N. Comparison of effectiveness of transcutaneous electrical nerve stimulation and kinesio taping added to exercises in patients with myofascial pain syndrome. J Back Musculoskelet Rehabil. 2017;30:291-8.

174. Doğan N, Şengül İ, Akçay-Yalbuzdağ Ş, Kaya T. Kinesio taping versus dry needling in the treatment of myofascial pain of the upper trapezius muscle: a randomized, single blind, prospective study. J Back Musculoskelet Rehabil. 2019;32(5):819-27.

175. Halski T, Ptaszkowski K, Słupska L, et al. Short-term effects of Kinesio taping and Cross taping application in the treatment of latent upper trapezius trigger points: a prospective, single-blind, randomized. Sham-Controlled Trial Evid Based Complement Alternat Med. 2015;2015:191925.

176. Hayta E, Umdu NM. A randomized trial to study the comparison of trigger point dry needling versus kinesio taping technique in myofascial pain syndrome during a 3-month follow-up. Int J Physiother. 2016;3:540-6.

177. Öztürk G, Külcü DG, Mesci N, Silte AD, Aydog E. Efficacy of kinesio tape application on pain and muscle strength in patients with myofascial pain syndrome: a placebo-controlled trial. J Phys Ther Sci. 2016;28(4): 1074-9.

178. Ptaszkowski K, Slupska L, Paprocka-Borowicz M, et al. Comparison of the short-term outcomes after Postisometric muscle relaxation or Kinesio taping application for normalization of the upper trapezius muscle tone and the pain relief: a preliminary study. Evid Based Complement Alternat Med. 2015; 2015:721938.

179. Rasti ZA, Shamsoddini A. The short-term and long-term effects of kinesio taping on the pain, range of motion and disability of neck in patients with myofascial pain syndrome: a randomized clinical trial. Trauma Mon. 2018;24: e69226.

180. González-Iglesias J, Fernández-de-Las-Peñas C, Cleland JA, Huijbregts $P$, Del Rosario Gutiérrez-Vega M. Short-term effects of cervical kinesio taping on pain and cervical range of motion in patients with acute whiplash injury: a randomized clinical trial. J Orthop Sports Phys Ther. 2009;39(7):515-21.

181. Bae Y. Change the myofascial pain and range of motion of the temporomandibular joint following kinesio taping of latent myofascial trigger points in the sternocleidomastoid muscle. J Phys Ther Sci. 2014; 26(9):1321-4.

182. Coskun Benlidayi I, Salimov F, Kurkcu M, Guzel R. Kinesio taping for temporomandibular disorders: single-blind, randomized, controlled trial of effectiveness. J Back Musculoskelet Rehabil. 2016;29(2):373-80.

183. Keskinruzgar A, Kucuk AO, Yavuz GY, Koparal M, Caliskan ZG, Utkun M. Comparison of kinesio taping and occlusal splint in the management of myofascial pain in patients with sleep bruxism. J Back Musculoskelet Rehabil. 2019;32(1):1-6.

184. Lietz-Kijak D, Kopacz $Ł$, Ardan R, Grzegocka M, Kijak E. Assessment of the short-term effectiveness of Kinesiotaping and trigger points release used in functional disorders of the masticatory muscles. Pain Res Manag. 2018;2018: 5464985.

185. Zhang XF, Liu L, Wang BB, Liu X, Li P. Evidence for kinesio taping in management of myofascial pain syndrome: a systematic review and metaanalysis. Clin Rehabil. 2019;33(5):865-74

186. Lee J, Yong M, Kong B, Kim J. The effect of stabilization exercises combined with taping therapy on pain and function of patients with myofascial syndrome. J Phys Ther Sci. 2012;24:1283-7.

187. Aleksiev AR. A novel physical therapy method of treating myofascial pain due to muscle spasm and shortening. Folia Med (Plovdiv). 2013;55(2):43-50.

188. Palmer S, Barnett S, Cramp M, Berry A, Thomas A, Clark EM. Effects of postural taping on pain, function and quality of life following osteoporotic vertebral fractures-a feasibility trial. Musculoskeletal Care. 2018;16(3):345-52.

189. Fousekis K, Billis E, Matzaroglou C, Mylonas K, Koutsojannis C, Tsepis E. Elastic bandaging for orthopedic- and sports-injury prevention and rehabilitation: a systematic review. J Sport Rehabil. 2017;26(3):269-78.

190. Lim EC, Tay MG. Kinesio taping in musculoskeletal pain and disability that lasts for more than 4 weeks: is it time to peel off the tape and throw 
it out with the sweat? A systematic review with meta-analysis focused on pain and also methods of tape application. Br J Sports Med. 2015; 49(24):1558-66.

191. Ramírez-Vélez R, Hormazábal-Aguayo I, Izquierdo M, González-Ruíz K,

Correa-Bautista JE, García-Hermoso A. Effects of kinesio taping alone versus sham taping in individuals with musculoskeletal conditions after

intervention for at least one week: a systematic review and meta-analysis. Physiotherapy. 2019;105(4):412-20.

192. Kim JY, Kim SY. Effects of kinesio tape compared with non-elastic tape on hand grip strength. J Phys Ther Sci. 2016;28(5):1565-8.

193. Xiang Y, He JY, Li R. Appropriateness of sham or placebo acupuncture for randomized controlled trials of acupuncture for nonspecific low back pain: a systematic review and meta-analysis. J Pain Res. 2017;11:83-94.

194. Chen ZX, Li Y, Zhang XG, et al. Sham Electroacupuncture methods in randomized controlled trials. Sci Rep. 2017:7:40837.

195. Alrwaily M, Timko M, Schneider M, et al. Treatment-based classification system for low Back pain: revision and update. Phys Ther. 2016;96(7): 1057-66.

196. Fritz JM, Brennan GP. Preliminary examination of a proposed treatmentbased classification system for patients receiving physical therapy interventions for neck pain. Phys Ther. 2007;87(5):513-24.

197. Stanton TR, Fritz JM, Hancock MJ, Latimer J, Maher CG, Wand BM, et al. Evaluation of a treatment-based classification algorithm for low back pain: a cross-sectional study. Phys Ther. 2011 Apr;91(4):496-509.

\section{Publisher's Note}

Springer Nature remains neutral with regard to jurisdictional claims in published maps and institutional affiliations.

Ready to submit your research? Choose BMC and benefit from:

- fast, convenient online submission

- thorough peer review by experienced researchers in your field

- rapid publication on acceptance

- support for research data, including large and complex data types

- gold Open Access which fosters wider collaboration and increased citations

- maximum visibility for your research: over $100 \mathrm{M}$ website views per year

At $\mathrm{BMC}$, research is always in progress.

Learn more biomedcentral.com/submissions 